\title{
Effective Prediction of Monthly Heat Transfer Characteristics in a Thin-Layer Cascade Reactor Subjected to Outdoor Conditions
}

\author{
Shehnaz Akhtar $\mathbb{D},{ }^{1}$ Haider Ali $\mathbb{D}{ }^{2}$ and Cheol Woo Park $\mathbb{D}^{1}$ \\ ${ }^{1}$ School of Mechanical Engineering, Kyungpook National University, 80 Daehakro, Bukgu, Daegu 41566, Republic of Korea \\ ${ }^{2}$ Department of Chemical Engineering, Norwegian University of Science and Technology, Trondheim, No. 7491, Norway \\ Correspondence should be addressed to Cheol Woo Park; chwoopark@knu.ac.kr
}

Received 14 October 2021; Revised 29 December 2021; Accepted 31 December 2021; Published 28 January 2022

Academic Editor: Yuanyuan Duan

Copyright (C) 2022 Shehnaz Akhtar et al. This is an open access article distributed under the Creative Commons Attribution License, which permits unrestricted use, distribution, and reproduction in any medium, provided the original work is properly cited.

\begin{abstract}
Algal biofuels are intriguingly a renewable energy source that could partially substitute fossil fuels, but further research is required to optimise the growth parameters and establish competitive large-scale cultivation systems. Algal growth is directly dependent on momentum, heat, and mass transfer within the photobioreactor and environmental conditions. Therefore, in this computational study, the heat transfer between the thin-layer cascade (TLC) reactor and its surrounding was reported based on static (location and reactor geometry) and dynamic (air temperature, solar irradiance, and wind velocity) parameters. The resulting model was validated using experimental data. The Nusselt number and the monthly average water temperature were computed to investigate the heat transfer phenomena between the TLC reactor and atmosphere. In addition, a novel corelation was used to estimate the evaporative losses from the TLC reactor. The effect of geometric properties (inclination angle of the reactor, water depth, and channel width) was evaluated on heat transfer. Results showed that heat transfer rate and the optimum water temperature for algal growth were significantly affected by hydrodynamics, environmental conditions, and reactor design. Water temperature decreased with the increase in channel width, water depth, and slope angle of the reactor. Furthermore, algal productivity declined with the increase in the amount of evaporated water.
\end{abstract}

\section{Introduction}

A strong interest in the cultivation of photoautotrophic microalgae is stimulated by their diverse applications: biofuels, chemicals, medicine, and food supplements are part of the nonexhaustive list [1]. Microalgae hold promise in the purification of contaminated and wastewater $[2,3]$. They are also being used in products for skin health and as a fertiliser. Over the last few years, due to the increasing concerns of global warming associated with excessive $\mathrm{CO}_{2}$ emissions and the decline in fossil fuels, microalgae have become an alternative source of energy $[4,5]$.

Different mass culture systems have been used for microalgal cultivation. To date, the intensive photobioreactor mostly used for large-scale production of microalgae is the open raceway pond. The main advantage of the raceway includes relatively low cost and simple design. However, as the culture thickness is high $(25-30 \mathrm{~cm})$ in raceway ponds, photo inhabitation is the major challenge that affects the photosynthesis phenomenon and limits algal productivity [6]. An alternate approach for commercialscale production of biomass is the thin-layer cascade (TLC) system, introduced by [7]. TLC systems are based on the circulation of a very small-layer thickness $(<1 \mathrm{~cm})$ over a flat inclined channel exposed to sunlight. As the light path is very short, light use is very effective and high biomass densities $(25-35 \mathrm{~g} / \mathrm{L})$ could be achieved [8-10]. TLC systems are characterised by highly turbulent flow, which limits the algal cell sedimentation, therefore increasing the frequency of exposition of single cell to sunlight [9].

Although algae are fast-growing phototrophic species with high photosynthetic performance, their growth is strongly affected by culture and environmental factors, such as light supply, temperature, nutrients, $\mathrm{pH}$, cultural depth, and $\mathrm{CO}_{2}$ availability [10]. Suboptimal temperature and the amount of light available to cells are the most significant of 
all the factors listed $[11,12]$. Algae grow as light intensity increases to a saturation (optimum) level, beyond which an increase in light level slows the rate of biomass growth. This phenomenon is referred to as photoinhibition, a significant challenge in outdoor systems because it limits algal cell photosynthetic efficiency and, consequently, biomass yield. Light attenuation occurs as the culture depth increases in the TLC reactor, thus reducing the local light penetration. A steep gradient in light attenuation is expected along the culture depth [13-15].

TLC systems with small culture thickness restrict the night biomass loss by respiration, whereas a rapid increase in the culture temperature at the start of the day inhibits strong photo inhabitation of algal growth [8]. Algal productivity is higher in TLC systems with small-layer thickness because of the more effective utilisation of solar irradiance [16]. Under optimal climate conditions, the increases in channel length, culture thickness, and slope angle cause a substantial increase in net areal biomass productivity because of the increase in photosynthetic efficiency. However, the night biomass loss increases with the increase in culture thickness [17].

The reactor's water temperature is a second growth limiting factor. It strongly influences cell chemical composition, nutrient and $\mathrm{CO}_{2}$ absorption, and the growth rate of all algal species. The geometrical design of the reactor, solar intensity, air temperature, wind speed, and evaporation affect the temperature of the reactor water [18]. Maximum utilisation of solar energy is achieved when the water temperature is optimal. Solar irradiance may become harmful as the water temperature drops below the optimal temperature range $\left(28^{\circ} \mathrm{C}-35^{\circ} \mathrm{C}\right)$ [19-22]. Therefore, maintaining an optimum temperature throughout the day and quickly reducing it at night are essential to maximising productivity [12]. The performance of the TLC system is also influenced by seasonal, climatic, and temperature fluctuations. Bosca et al. [23] reported that photosynthetic activity is remarkably increased when algal cells are mixed, especially between sunrise and sunset hours, under optimal temperature conditions.

Evaporative heat losses play a significant role in the exchange of thermal energy between the reactor and its environment. TLC systems are quickly heated by solar rays; however, at high temperatures, they are also spontaneously cooled by evaporation [14]. Evaporative cooling results in considerable water loss from the reactor and affects the water temperature. Due to the significant water losses to the environment, the TLC system uses $\mathrm{CO}_{2}$ less effectively [17]. Comprehending the parameters that affect thermal conditions and, consequently, culture growth necessarily requires heat transfer calculations between the reactor and its environment due to the effects produced by the convection with air, evaporation, and radiation to the atmosphere and sun. However, experimental estimation of the heat transfer between the reactor and the environment is difficult and expensive because of the complex variations in different parameters, including geometrical design of the reactor, hydrodynamics, and environmental conditions (such as solar intensity, wind speed, air temperature, and relative humidity).
Modeling heat transfer phenomena in outdoor TLC reactors using computational fluid dynamics is a cost-effective technique to maximise algal productivity under real environmental conditions. Numerous computational approaches have been proposed to model algal productivity under time-dependent conditions of solar irradiance and air temperature for traditional raceway ponds [24-26]. However, despite its high potential for efficient biomass production, TLC has received little attention in numerical studies. Based on the above discussion, computational studies on the heat transfer between TLC reactor and atmosphere are lacking in the literature. There is limited data available on thermal modeling of TLC reactor, and previous studies only considered limited design and operational parameters. To the best of the author's knowledge, no previous study has investigated the heat transfer phenomenon in TLC reactors with the effect of reactor geometry, hydrodynamics, and environmental conditions. In this study, the numerical simulations are performed under a wide range of geometric properties of the reactor (channel width, slope angle, and water depth) hydrodynamics and meteorological variables (relative humidity, airspeed, solar intensity, and air temperature) to provide a more reliable estimation of heat transfer between the TLC reactor and atmosphere. Initially, the fluid dynamic characteristics of water and air were computed. These velocity fields were then used to solve the heat transport and evaporation equations simultaneously. The monthly average water temperature, Nusselt number $(\mathrm{Nu})$, and monthly evaporated water were evaluated to investigate the heat losses between the reactor water and atmosphere. Furthermore, various design parameters of TLC reactor (such as reactor depth, slope angle, and channel width), hydrodynamics, and environmental conditions were considered to analyse the effect on the preceding heat transfer parameters.

\section{Mathematical Modeling}

In this study, a version of the TLC photobioreactor, according to Apel et al. [14], was used as a basis for the simulation. It consists of several modules: inlet module, upper channel, flow reversal module, lower channel, and retention tank. The upper and lower channels of the reactor are the main cultivation units of the reactor inclined in the opposite direction. The length and width of the upper and lower channels are 4 and $1 \mathrm{~m}$, respectively. The first module in the reactor is the inlet module, which distributes the water over the upper channel. The angle of the inlet module to the upper plate is $55^{\circ}$. A drip edge at the end of the upper channel is positioned for smooth flow into the reversal module (length: $5 \mathrm{~cm}$, angle to vertical: $10^{\circ}$ ), which redirects the fluid into the lower channel. The bottom of the reversal module is sloped in the flow direction to facilitate gravitydriven flow to the lower channel, as shown in Figure 1. The numerical values of the important geometrical parameters of the TLC reactor are given in Table 1.

The effect of reactor geometry on heat transfer was studied using a dimensionless quantity, that is, aspect ratio (AR): 


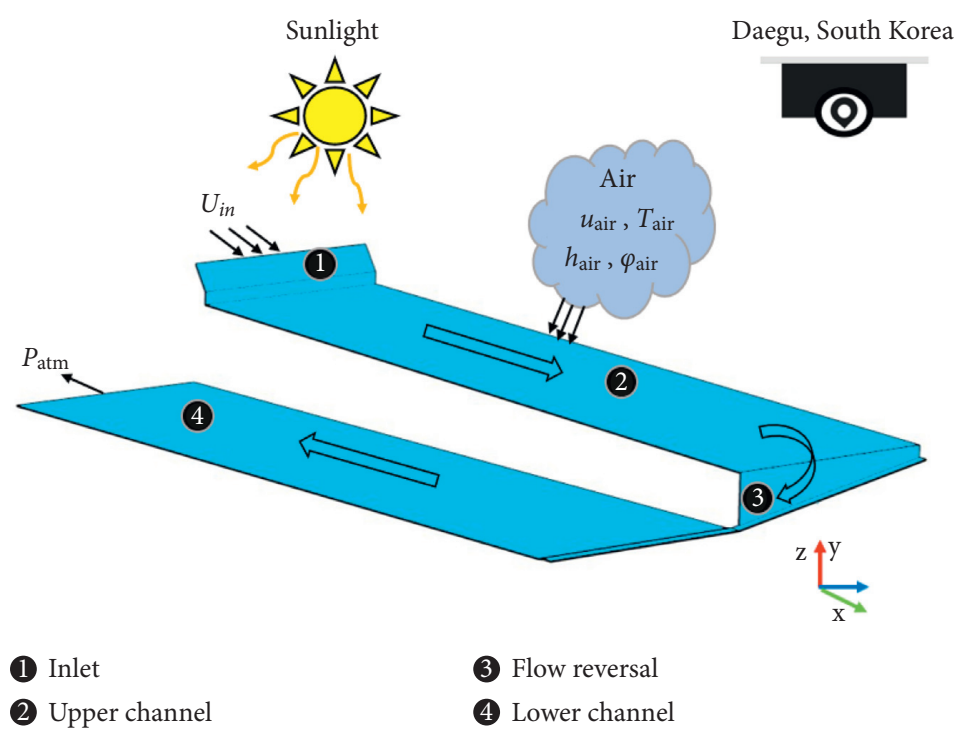

(a)

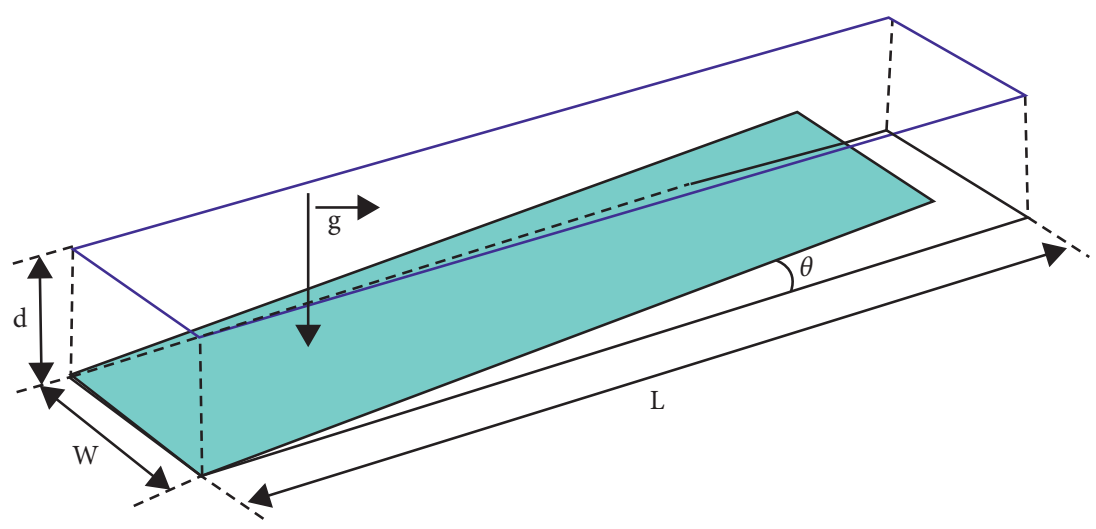

(b)

FIgURE 1: (a) Computational model of thin-layer cascade reactor inclined at $1^{\circ}$; (b) sketch of the channel of the reactor. The coloured surface shows the liquid surface parallel to the wall and inclined by an angle with respect to the horizontal dashed surface.

TABLE 1: Summary of important parameters of the thin-layer cascade reactor.

\begin{tabular}{lr}
\hline Parameter & Value \\
\hline Aspect ratio & $\{180,260,340\}$ \\
Water depth & $\{5.6 \mathrm{~mm}, 7.5 \mathrm{~mm}, 10 \mathrm{~mm}\}$ \\
Slope angle & $\left\{1^{\circ}, 2^{\circ}\right\}$ \\
Reynolds number & $\{9000,14000\}$ \\
\hline
\end{tabular}

$$
\operatorname{AR}=\frac{(\text { channel width })}{(\text { channel depth })}=\frac{W}{d}
$$

In this study, three distinct AR values (180, 240, and 360) with different water depths, monthly variations in solar irradiance, relative humidity, wind speeds, and ambient temperatures were included to examine their effects on heat transfer parameters. Initially, the fluid dynamic properties of water and air were computed. These velocity fields were then used to solve the equations for heat transfer and evaporation simultaneously. The influence of algal cell presence and motion (cell concentration dispersion) on the heat transfer phenomenon is beyond the scope of this work, hence not included.
2.1. Hydrodynamic Modeling. Wilcox's $k-\omega$ turbulence model was used to model turbulence in the reactor and surrounding air. The $k-\omega$ turbulence model is a suitable choice for fluids characterised by a turbulent flow with a high Reynolds number ( $\mathrm{Re}$ ) in open channel flows and it works well near the walls $[18,27,28]$. The Re based on hydraulic diameter was used to evaluate flow behavior in an open channel as follows:

$$
\begin{gathered}
D_{h}=\frac{4 W D}{2 d+W}, \\
\operatorname{Re}=\frac{\rho D_{h} U}{\mu} .
\end{gathered}
$$


The flow in the reactor is turbulent with a range of $\mathrm{Re}$ between 9,500 and 14,200 [29]. The continuity and momentum equations for the $k-\omega$ turbulence model are given as follows:

$$
\begin{aligned}
\rho \nabla \cdot(u) & =0 \\
\rho \frac{d u}{d t}+\rho(u . \nabla) u & =\nabla \cdot\left[-\rho I+\left(u+\mu_{T}\right)\left(\nabla_{u}+\left(\nabla u^{T}\right)\right)\right]+F,
\end{aligned}
$$

where $u$ denotes velocity vector $(\mathrm{m} / \mathrm{s}), I$ is the identity matrix, and $F$ is the body force $\left(\mathrm{N} / \mathrm{m}^{3}\right)$. The $k-\omega$ turbulence model uses two equations (turbulent kinetic energy and dissipation rate) to represent the turbulence properties of the flow. The governing equations of the turbulent kinetic energy and turbulent dissipation rate for $k$ - $\omega$ turbulence model are as follows:

$$
\begin{gathered}
\rho \frac{\partial k}{\partial t}+\rho(u . \nabla) k=\nabla \cdot\left[\left(\mu+\mu_{t} \sigma_{k}^{*}\right) \nabla k\right]+P_{k}-\beta_{0}^{*} \rho \omega k, \\
\rho \frac{\partial \omega}{\partial t}+\rho(u . \nabla) \omega=\nabla \cdot\left[\left(\mu+\mu_{t} \sigma_{\omega}\right)\right]+\alpha \frac{\omega}{k} P_{k}-\rho \beta_{0} \omega^{2},
\end{gathered}
$$

where $\sigma_{\omega}$ represents the Prandtl number for dissipation rate and $\sigma_{k}$ is the Prandtl number for kinetic energy. Based on experimental data of Wilcox's following values were assigned to the model constant in the present study [28]: $\alpha=0.55, \sigma_{k}^{*}=0.5, \sigma_{\omega}=0.5$, and $\beta^{*}=0.09$. The turbulent viscosity defined by the $k-\omega$ turbulence model is as follows:

$$
\mu_{t}=\rho \frac{k}{\omega},
$$

where $\mu_{t}$ represents the turbulent viscosity (Pa.s), $\omega$ is the dissipation rate $(1 / \mathrm{s}), k$ denotes the turbulent kinetic energy $\left(\mathrm{m}^{2} / \mathrm{s}^{2}\right)$, and $\rho$ is the density $\left(\mathrm{kg} / \mathrm{m}^{3}\right)$. The production term is given as follows:

$$
P_{k}=\mu_{T}\left[\nabla u:\left(\nabla u+\left(\nabla u^{T}\right)\right)\right] .
$$

2.2. Heat Transfer Modeling. The heat transfer between the TLC reactor water surface and surroundings was modeled considering the effect of radiation, convection, and evaporation. A detailed description for modeling of radiation, convection, and evaporation is given in the subsequent sections.

2.2.1. Radiation. The heat transfer in fluids featured with surface-to-surface radiation of the COMSOL-Multiphysics (5.5) heat transfer module was employed to model radiation heat transfer in the TLC reactor [30]. A comprehensive description and settings for surface-to-surface radiation could be found in the COMSOL-Multiphysics (5.5) user manual for the heat transfer module. The radiation source term $(q)$ is expressed by the following equation:

$$
q=G-J
$$

where $q$ represents the heat flux $\left(\mathrm{W} / \mathrm{m}^{2}\right), G$ denotes the total incoming radiation $\left(\mathrm{W} / \mathrm{m}^{2}\right)$, and $J$ represents the total radiative flux or radiosity $\left(\mathrm{W} / \mathrm{m}^{2}\right)$. The governing equation for incoming radiative heat flux $(G)$ is as follows:

$$
G=G_{\mathrm{amb}}+G_{\mathrm{ext}},
$$

where $G_{\mathrm{amb}}$ and $G_{\text {ext }}$ represent the ambient radiation and irradiation from external sources $\left(\mathrm{W} / \mathrm{m}^{2}\right)$, respectively. The governing equation for ambient radiation $G_{\mathrm{amb}}$ is given as follows:

$$
G_{\mathrm{amb}}=n^{2} F_{\mathrm{amb}} \sigma T_{\mathrm{amb}}^{4},
$$

where $n$ and $F_{\text {amb }}$ represent the transparent medium refractive index and ambient view factor (1), respectively; $\sigma$ denotes the Stefan-Boltzmann constant $\left(5.67 \times 10^{-8} \mathrm{~W} / \mathrm{m}^{2}\right.$ $\left.\mathrm{K}^{4}\right) ; T_{\mathrm{amb}}$ is the ambient temperature $(\mathrm{K})$. The water in the TLC reactor exhibited a surface emissivity of 0.92 and a solar absorptivity of 0.8 [31].

Geographic location, time of day, and year all influence the amount of solar radiation incident on surfaces, such as in the TLC system. In the analysis, a $3 \mathrm{D}$ solar position was described by an external radiation source to estimate the external radiative heat source induced by the sun. The solar position was described in terms of geographical location (i.e., latitude, longitude, and time zone), date (i.e., day, month, and year), local time (i.e., hour, minutes, and seconds), and solar irradiance $I_{s}$. The governing equation for the external radiation source $G_{\text {ext }}$ is described as follows:

$$
G_{\text {ext }}=F_{\text {ext }} \cdot I_{s} \text {, }
$$

where $G_{\text {ext }}$ and $I_{s}$ represent the external radiation source and incident radiative intensity from the sun $\left(\mathrm{W} / \mathrm{m}^{2}\right)$, respectively. The monthly values of radiative intensity from the sun used in the current simulations are given in Table 2.

2.2.2. Convection. Heat is also transported from the culture medium to the surrounding environment through convective heat transfer [32]. The heat transfer in fluids featured with convective heat flux boundary condition of the COMSOL-Multiphysics (5.5) heat transfer module was used to model the convective heat transfer in the TLC reactor [30]. The governing equation to define the convective heat flux in the reactor is given as follows:

$$
q=h\left(T_{\mathrm{amb}}-T_{\mathrm{srf}}\right),
$$

where $q$ represents the heat flux $\left(\mathrm{W} / \mathrm{m}^{2}\right) ; h$ denotes the heat transfer coefficient of air $\left(20 \mathrm{~W} /\left(\mathrm{m}^{2} \mathrm{~K}\right)\right) ; T_{\mathrm{amb}}$ and $T_{\text {srf }}$ represent the ambient air temperature and water surface temperature $(\mathrm{K})$, respectively.

The air temperature in outdoor photobioreactors does not remain constant; rather, it varies sinusoidally during the day [33]. The ambient air temperature drops to the lowest value around 3:00-4:00 at night and then rises to a maximum value around 12:00-15:00 afterwards. Therefore, a time-dependent cosine function is defined in this study for the approximation of daily variation of ambient temperature as follows [34]: 
TABLe 2: Monthly average weather data for Daegu, South Korea (from January 2017 to December 2017).

\begin{tabular}{lcccc}
\hline Month & $u_{a}(\mathrm{~m} / \mathrm{s})$ & $I_{s}\left(\mathrm{~W} / \mathrm{m}^{2}\right)$ & $T_{a}(\mathrm{~K})$ & $\varphi(\%)$ \\
\hline January & 2.5 & 112 & 274 & 52 \\
February & 2.8 & 168 & 276 & 46 \\
March & 2.3 & 183 & 281 & 50 \\
April & 2.3 & 222 & 289 & 52 \\
May & 2.3 & 249 & 294 & 52 \\
June & 2.4 & 256 & 296 & 60 \\
July & 1.9 & 178 & 301 & 75 \\
August & 2.2 & 200 & 300 & 75 \\
September & 1.8 & 183 & 295 & 68 \\
October & 1.8 & 127 & 289 & 71 \\
November & 2 & 124 & 281 & 53 \\
December & 2.6 & 107 & 276 & 46 \\
\hline
\end{tabular}

$$
T_{\mathrm{amb}}=T_{a}+3 \times \cos \left(2 \times \pi \times \frac{(t-14)}{24}\right),
$$

where $T_{\mathrm{amb}}$ and $T_{a}$ represent the ambient temperature and monthly mean ambient temperature (K), respectively, and $t$ is the time in hours $(h)$. An analytical function was used to define the mathematical function of (12). Table 2 shows the monthly mean ambient air temperature used in the present simulations.

2.2.3. Evaporation. Thermal energy could be lost from the system by evaporation, which cools the reactor water in addition to convective cooling by the surrounding air. Evaporative heat flux depends upon the amount of water evaporated from the reactor surface. The fraction of convective and diffusive flux normal to the reactor surface contributes to evaporative heat flux [35]. Turbulent flow $k-\omega$, the heat transfer in fluids, and the transport of diluted species module in COMSOL-Multiphysics (5.5) were employed to model the evaporation $[30,36,37]$. The governing equation for evaporative heat flux is given as follows:

$$
q=H_{\text {vap }}\left(-D \nabla_{C}+u_{a} c\right),
$$

where $H_{\text {vap }}$ represents the latent heat of vaporisation (kJ/ $\mathrm{mol}), D$ denotes the diffusion coefficient $\left(\mathrm{m}^{2} / \mathrm{s}\right), c$ shows the water vapor concentration in atmospheric air $\left(\mathrm{mol} / \mathrm{m}^{3}\right)$, and $u_{a}$ is the mean air speed $(\mathrm{m} / \mathrm{s})$. Table 2 presents the monthly mean air speed $u_{a}$ and relative humidity $(\varphi)$ used in the simulation of Daegu, South Korea, from January 2017 to December 2017.

The transport of diluted species feature of the COMSOLMultiphysics (5.5) chemical species transport module was employed to estimate the amount of evaporated water in the atmosphere. The ideal gas law at saturation pressure was used to define the source term for water vapor concentration $\left(c_{\text {vap }}\right)$ present on the reactor surface $[35,38]$.

$$
C_{\text {vap }}=\frac{p_{\text {sat }}}{R_{g} T}
$$

where $c_{\text {vap }}$ represents the concentration of water vapor (mol/ $\left.\mathrm{m}^{3}\right), p_{\text {sat }}$ denotes saturation pressure $(\mathrm{Pa}), R_{g}$ is the ideal gas constant $(\mathrm{J} / \mathrm{mol} \mathrm{K})$, and $T$ is the temperature $(\mathrm{K})$. The diffusion coefficient $(D)$ is defined using the turbulent viscosity because of the turbulent flow in the reactor and air as follows:

$$
D=\frac{\mu_{T}}{S c_{T}},
$$

where $D$ represents the diffusion coefficient $\left(\mathrm{m}^{2} / \mathrm{s}\right), \mu_{T}$ denotes turbulent viscosity $(\mathrm{Pa} \cdot \mathrm{s})$, and $S c_{T}$ represents the Schmidt number (1), which is the ratio of momentum and mass diffusivities. Evaporative cooling could be beneficial in several conditions, such as preventing reactor overheating and controlling the water temperature to the optimum value. However, microalgal culture diminishes due to the significant water loss from the reactor surface. Additional water is usually added daily to recover the water loss [39]. Therefore, estimating the amount of water evaporated is important to achieve an efficient design of a TLC reactor. In this study, the following relation was used to compute the amount of evaporated water $\left(m_{w}\right)$ from the reactor in the air:

$$
m_{w}=\int_{t_{1}}^{t_{2}} \iint_{s}^{i} j \cdot M_{w} \mathrm{~d} A \mathrm{~d} t
$$

where $m_{w}$ is the amount of evaporated water $(\mathrm{kg}), j$ is the diffusive flux in the $z$-direction $\left(\mathrm{mol} / \mathrm{m}^{2} \mathrm{~s}\right), M_{w}$ is the molar mass of water $(\mathrm{kg} / \mathrm{mol}), t$ is time (s), and $s$ is the boundary surface of the TLC reactor $(m)$.

\section{Numerical Methods}

The commercial code COMSOL-Multiphysics (5.5) was employed to investigate the heat transfer between the TLC reactor and atmosphere with the effect of reactor geometry, hydrodynamics, and environmental conditions. The weather data for Daegu, South Korea, located at $\left(35^{\circ} 53^{\prime} 13^{\prime \prime} \mathrm{N}\right.$; $128^{\circ} 37^{\prime} 28^{\prime \prime}$ E) was obtained from the annual climatological report (11-1360000-000016-10) of the Korea Meteorological Administration in Seoul, South Korea, from January 2017 to December 2017 [40]. The climate data (averaged monthly air temperature, solar radiation, air speed, and relative humidity) provided in Table 2 were used in the simulations. The $k-\omega$ turbulence model was used to model the airflow and the turbulence in the reactor. Time-dependent heat transfer with surface-to-surface radiation and the transport of diluted species interface were simulated with the effects of hydrodynamics (air and water flow fields) and environmental conditions. The flow fields from the $k-\omega$ turbulence model were used as input for the heat transfer and transport of diluted species equations.

In COMSOL-Multiphysics built-in feature, physicscontrolled mesh was used to discretise the computational domain. Grid refining is adopted close to the reactor walls to allow the $y+$ values to be in the correct range (30-50) and capture the flow and thermal fields in those regions precisely. To ensure high accuracy of results under minimal computational resources, a grid independence test was performed by varying the mesh elements with a factor of three under the same computational resources. Three different mesh sizes 
were adopted, namely, fine (total number of elements $=308,118$ ), finer (total number of elements $=908,118$ ), and extra fine (total number of elements $=1,206,326$ ). Examples of results for the reactor average water temperature during the day and night based on the entire reactor volume are given in Table 3. Only a slight difference could be observed for the prediction of reactor water temperature. Therefore, an extra fine mesh was retained for further simulations. All the simulations were carried out in an Intel Core i7-9700K $3.90 \mathrm{GHz}$ processor with a 64 GB RAM operating system.

\section{Results and Discussion}

The results of present study are validated against experimental data to quantify modeling error. A comparison of the present numerical study and experimental study by Apel et al. [14] is illustrated in Figure 2. The simulation results agree well with the experimental results and the maximum percentage error of computed water temperature from experimental data is $0.62 \%$. The heat transfer between outdoor TLC systems and their surroundings is influenced by a range of operational and seasonal variables. The seasonal variables include ambient air temperature, air speed, relative humidity, and solar radiation. Therefore, simulations were performed to investigate the heat transfer in an outdoor TLC system with its environment. The results in terms of monthly average water temperature, $\mathrm{Nu}$, evaporated water, and temperature distribution inside the reactor were presented under the influence of various geometrical parameters, namely, the inclination angle of the reactor, channel width, and water depth. Furthermore, the effect of flow properties on the abovementioned parameters was also discussed in the subsequent sections.

4.1. Water Temperature. Reactor water temperature is one of the important algal growth limiting factors. It strongly influences cell chemical composition, nutrient uptake, $\mathrm{CO}_{2}$ absorption, and the growth rate of all algae species. Therefore, the effect of various geometric and flow properties on the average water temperature of the reactor is presented in the following section.

4.1.1. Effect of Geometric Properties. Figure 3 shows the average water temperature in each channel of the reactor based on monthly average solar irradiance, ambient temperature, relative humidity, and wind speed over the course of a year for the reactor inclined at angles of $1^{\circ}$. The water temperature in the lower channel is lower than that in the upper channel. The possible reason could be attributed to the geometrical shape of the reversal module, which directs the fluid in the lower channel by increasing the temperature fluctuations in this channel. The maximum temperature difference between the upper and lower channels for the reactor inclined at $1^{\circ}$ was observed during the summer season from June to August. The effect of temperature in the upper and lower compartments of the reactor is likely to be minuscule, particularly for the reactor inclined at $1^{\circ}$.
TABle 3: Grid independence test (water depth $=5.6 \mathrm{~mm}$, slope angle $=1^{\circ}$, aspect ratio $=180$, and $\left.\operatorname{Re}=9000\right)$ for water temperature averaged on the entire reactor volume.

\begin{tabular}{lcc}
\hline No. of mesh elements & \multicolumn{2}{c}{$\begin{array}{l}\text { Average water temperature } \\
\text { for the month of June (K) }\end{array}$} \\
& Day & Night \\
\hline Fine mesh (308118) & 298.6270 & 295.7801 \\
Finer mesh (908118) & 297.2642 & 294.2975 \\
Extra fine mesh (1206326) & 297.1620 & 294.1389 \\
\hline
\end{tabular}

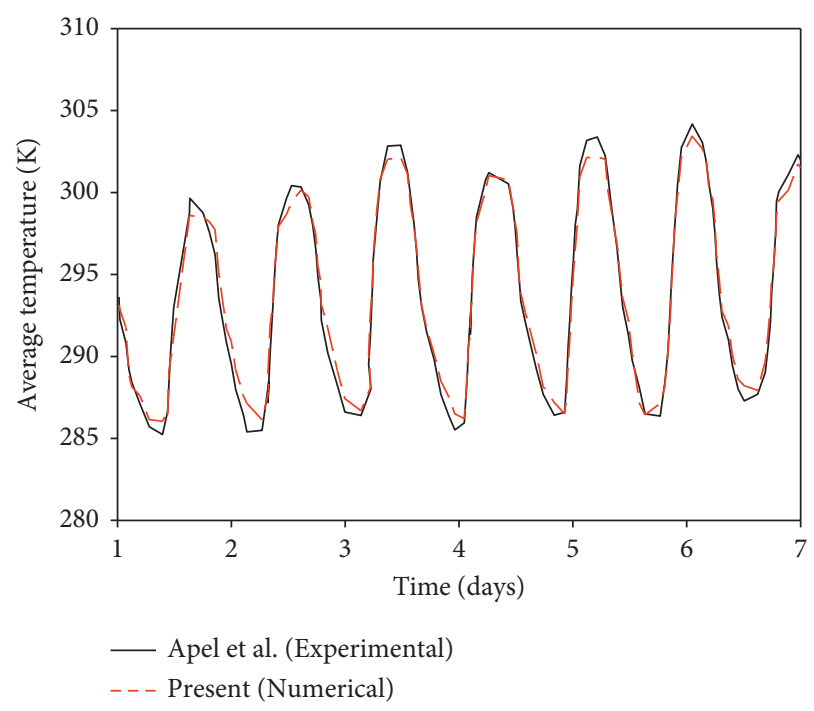

Figure 2: Comparison of present numerical study with experimental results of Apel et al. [14].

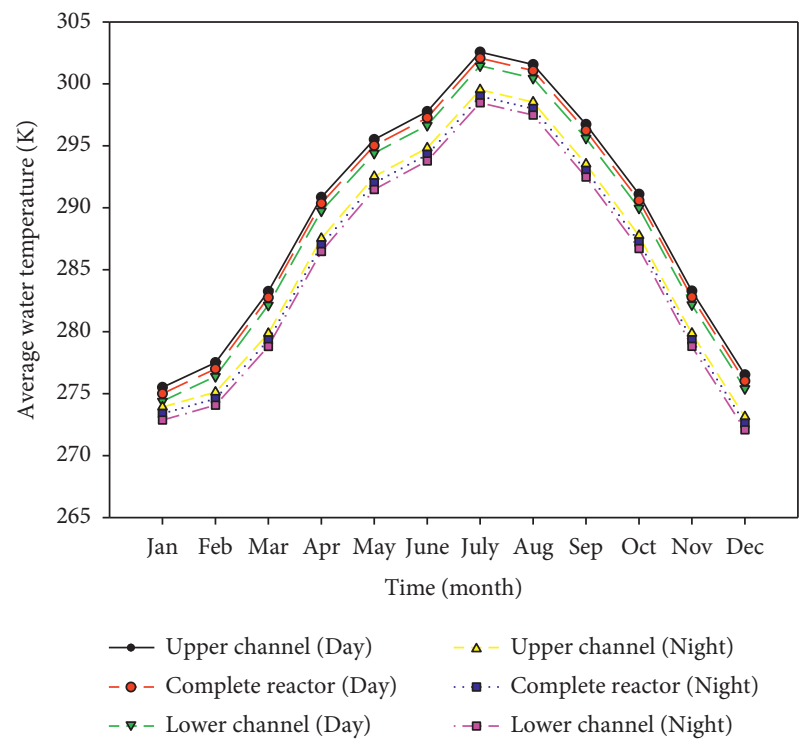

FIgURE 3: Average water temperature for reactor inclined at $1^{\circ}$, $\mathrm{Re}=9000, \mathrm{AR}=180$, and water depth of $5.6 \mathrm{~mm}$.

Therefore, only the complete reactor is discussed in the succeeding sections.

The effect of the inclination angle of the reactor on average water temperature at a constant water depth of $5.6 \mathrm{~mm}, \mathrm{AR}=180$, and $\mathrm{Re}$ of 9000 is presented in Figure 4 . 


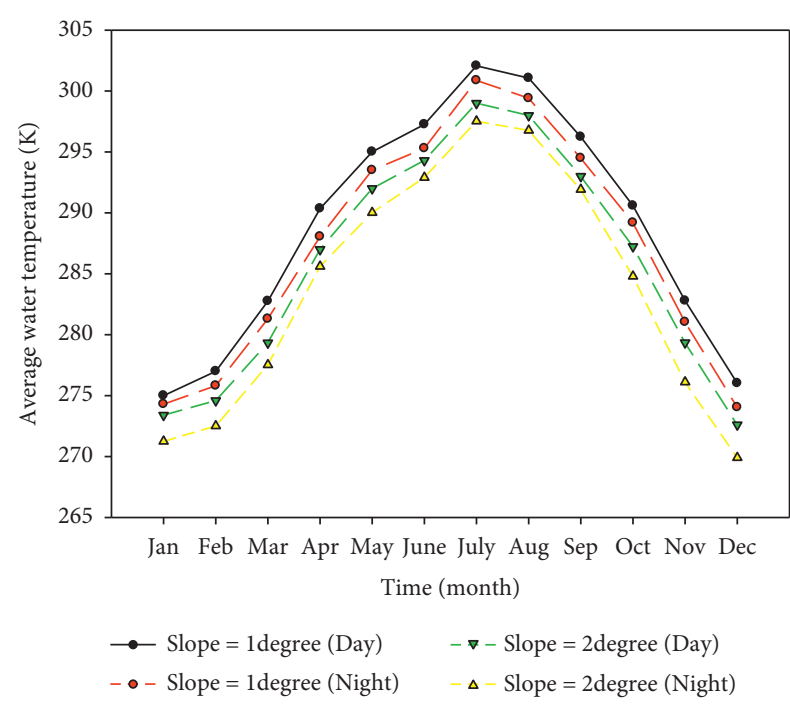

FIgURE 4: Effect of the inclination angle of the reactor on average water temperature at $\operatorname{Re}=9000$, water depth $=5.6 \mathrm{~mm}$, and aspect ratio $=180$.

The reactor water temperature in spring and summer is higher than in winter and fall, as shown in Figure 4. The high ambient air temperature and solar irradiance in summer and spring periods enhanced the radiative heat transfer, resulting in an increase in water temperature. The increase in the slope angle of the reactor increased the turbulence in the flow, which improved convective heat transfer by providing momentum for the warm liquid to come to the surface of the reactor and contact with air, allowing it to cool more rapidly. As the faster-moving molecules escaped, the remaining molecules exhibited lower average kinetic energy, and the temperature of the liquid decreased. The greater the temperature difference between water and air is, the faster the heat could escape from the reactor [35]. The lower value of air temperature and solar radiation during the winter months resulted in decreased water temperature. Therefore, during these months, microalgal growth rates may be hindered due to reduced solar radiation and air temperature, which results in decreased optimum water temperature.

Figure 5 shows the water temperature distribution of the air-water surface at a Re of 9000 for the reactors inclined at $1^{\circ}$ and $2^{\circ}$ in June (daytime). The upper channel of the reactor exhibited nearly a uniform temperature distribution. Pronounced fluctuation in temperature was observed for the reactor inclined at a higher slope angle. These fluctuations were more visible in the lower channel of the reactor, which could be attributed to the geometrical shape of the flow reversal module that directs the fluid in the lower channel by increasing the flow velocity. Moreover, the increase in inclination angle of the reactor resulted in increased air-water surface movement, thus promoting heat transfer between the reactor water and atmosphere, resulting in increased temperature fluctuations.

Figure 6 shows the effect of different ARs on the monthly average water temperature at a water depth of $5.6 \mathrm{~mm}$ and Re of 9000. Figure 6 clearly depicts that from June to August, the water temperature reached the optimum value. Since microalgal cultivation is highly temperature-dependent, the optimal cultivation temperatures achieved during the summer season are favourable for algae growth [41, 42]. The lower solar intensities and ambient air temperature during the winter months and at night increased convective heat transfer during the winter season and night. Consequently, for all the ARs, higher convective heat transfer caused the water temperature to drop by around $6^{\circ} \mathrm{C}$ at night. In addition to radiative and convective heat transfers, evaporation affected the water temperature of the reactor. Higher evaporative cooling in the reactor with larger ARs significantly reduced the water temperature. The water temperature was higher in the reactor with $\mathrm{AR}=180$ than that in wide reactor models because of low heat transfer (convection and evaporation) between the reactor and atmosphere. This result suggested that TLC systems with large ARs are unsuitable for microalgal cultivation because of low water temperatures.

The effect of ARs on the temperature distribution (K) of the air-water surface at a Re of 9000 and a water depth of $5.6 \mathrm{~mm}$ in June (daytime) is shown in Figure 7. The increase in AR also increased the fluctuations in temperature because of the high-water surface area, which further decreased the water temperature. Lowe variance in temperature of the reactor with narrow channel helped to achieve optimum water temperature and as a result, the photosynthetic efficiency of the algal cells significantly increased [43]. However, the $\mathrm{CO}_{2}$ absorption from the environment to the reactor with the narrow channel is less than that with a wide channel. Therefore, a suitable AR must be selected to maintain the optimum water temperature and increase the $\mathrm{CO}_{2}$ absorption from the atmosphere.

The effect of water depth on the average water temperature at a $\mathrm{Re}$ of 9000 and $\mathrm{AR}=180$ for representative months of the year is presented in Figure 8. During summer, solar radiation and air temperature are comparatively high in outdoor reactors and radiation and convection occur at the surface; as a result, the water temperature rises much faster at the surface than in the deeper reactors. Likewise, in winter, heat escapes from the surface, causing the temperature of the water near the surface to decrease more rapidly. Furthermore, the higher water temperature values in TLC systems with small water depth could be attributed to high solar radiation absorbance. At the depth of $5.6 \mathrm{~mm}$, the water temperature closely followed the ambient air temperature during the day. However, as the water depth increased, the reactor volume increased, causing a significant drop in water temperature due to the high heat transfer rate. For instance, during the month of June, the water temperature decreased at approximately $1.26^{\circ} \mathrm{C}$ during the day with the increase in water depth from $5.6 \mathrm{~mm}$ to $7.5 \mathrm{~mm}$. By contrast, the temperature reduced to $2.26^{\circ} \mathrm{C}$ with the increase in water depth from $7.5 \mathrm{~mm}$ to $10 \mathrm{~mm}$. At night, the reactor depth of $10 \mathrm{~mm}$ recorded a decrease of approximately $3^{\circ} \mathrm{C}$ in water temperature. The increase in water depth reduced the sunlight penetration in the reactor and the average irradiance received by algal cells at the bottom surface decreased. As the solar intensity was attenuated with depth, the results indicated that the water depth may be 
A 299

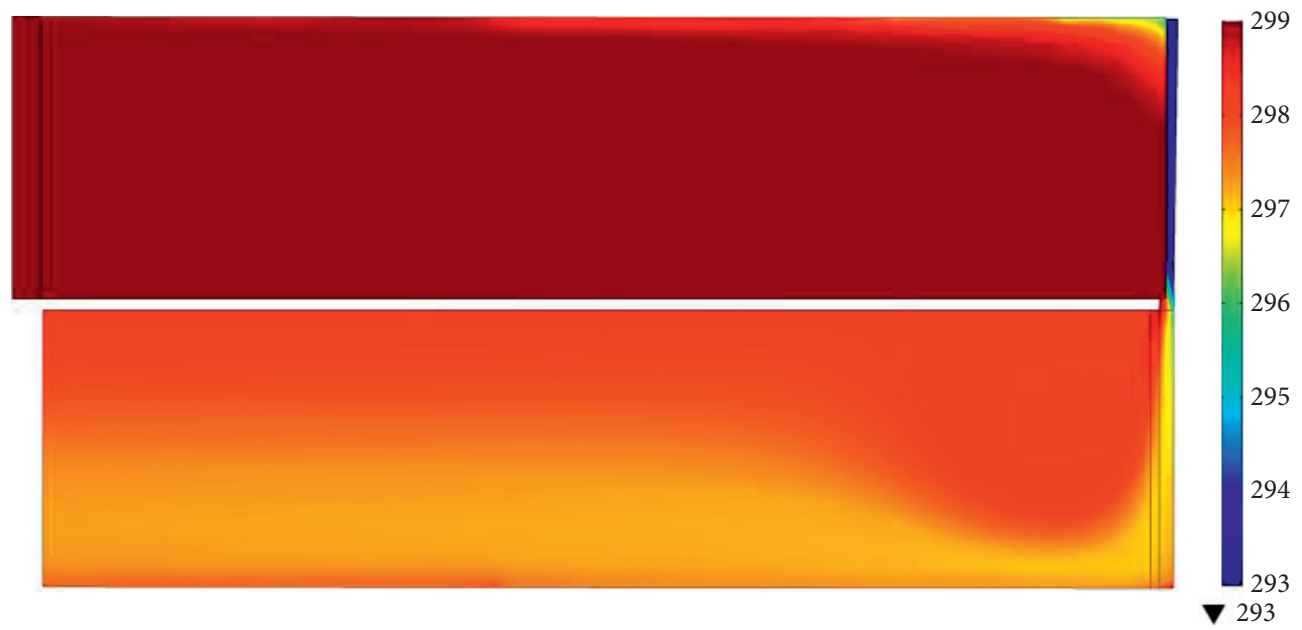

(a)

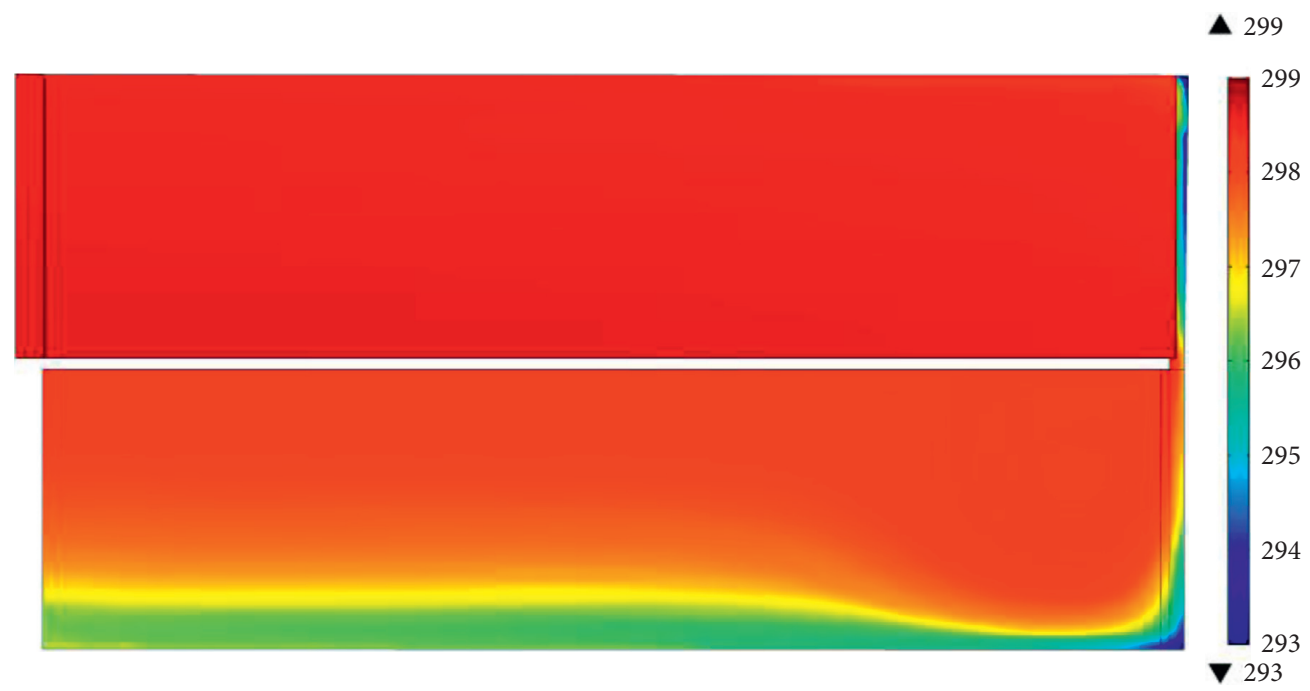

(b)

FIGURE 5: Effect of the inclination angle of the reactor on air-water surface temperature distribution $\mathrm{K}$ at $\mathrm{Re}=9000$, water depth $=5.6 \mathrm{~mm}$, and aspect ratio $=180$ for reactor inclined at (a) $1^{\circ}$ and (b) $2^{\circ}$ in June (XY-plane).

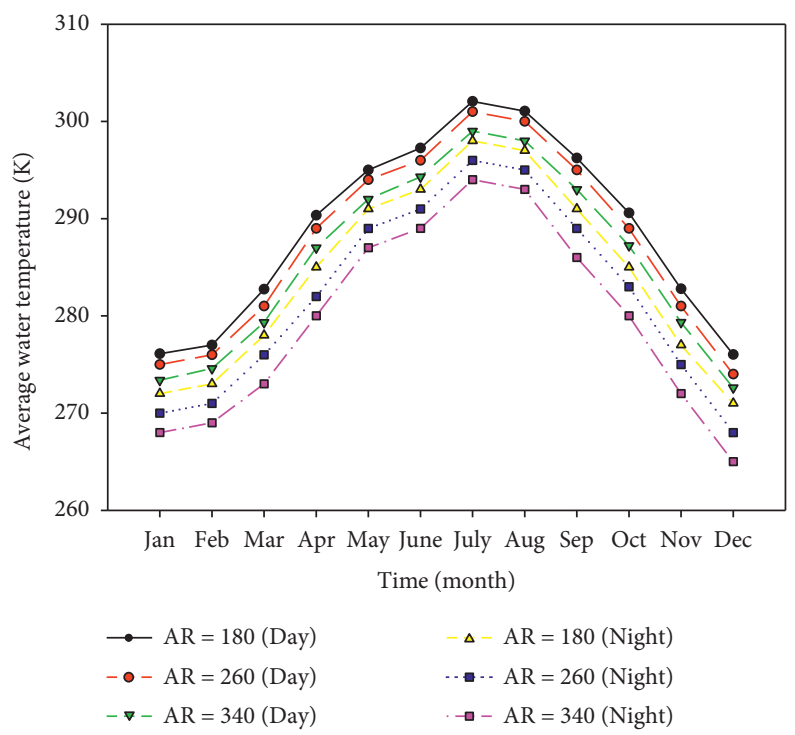

FIGURE 6: Effect of aspect ratio on average water temperature for reactor inclined at $1^{\circ}, \mathrm{Re}=9000$, and water depth $=5.6 \mathrm{~mm}$. 


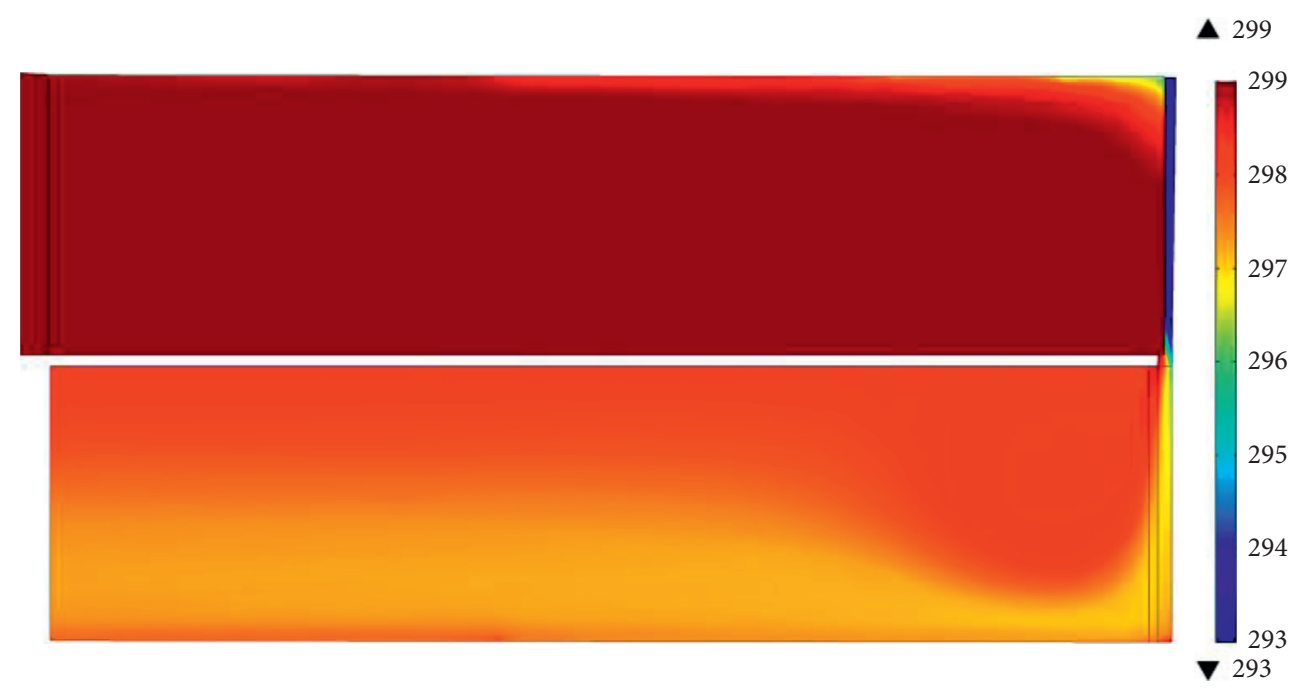

(a)

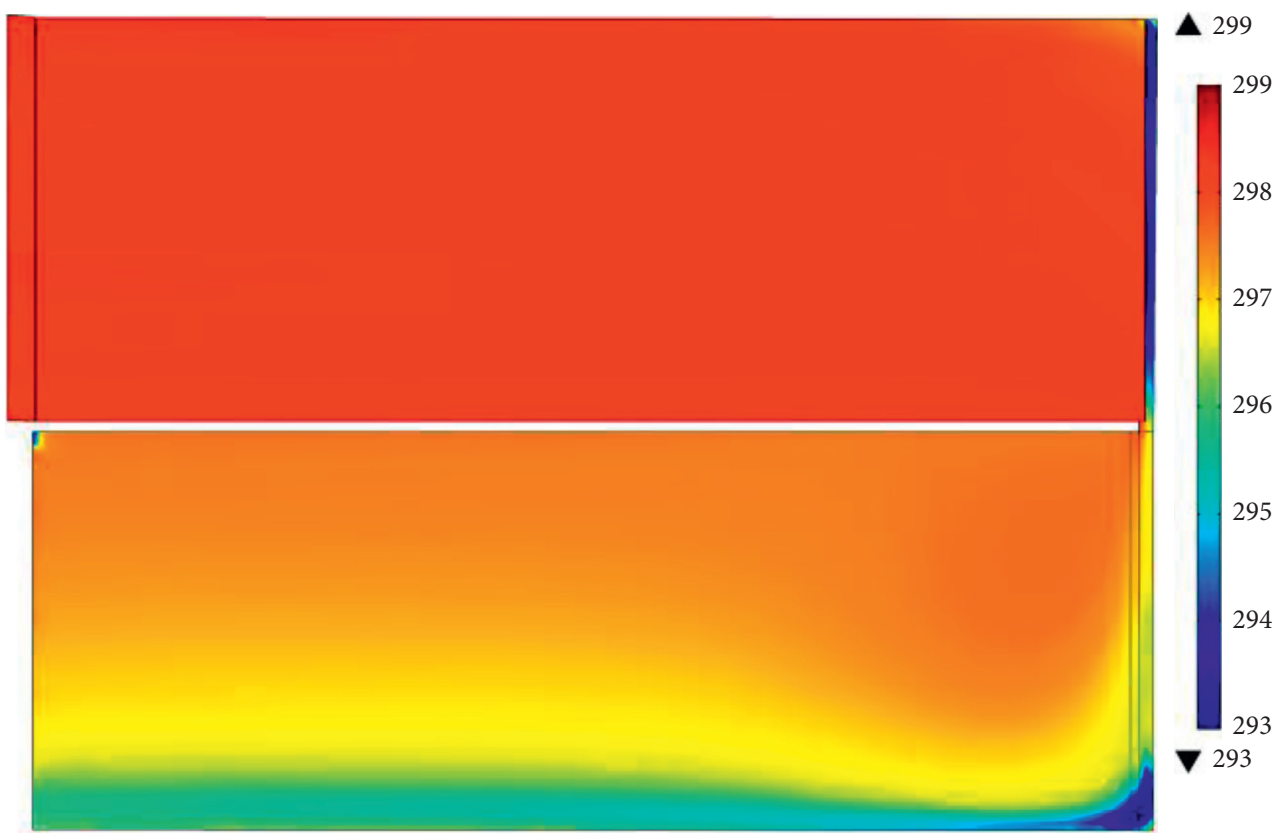

(b)

FIGURE 7: Effect of aspect ratio on air-water surface temperature distribution $\mathrm{K}$ for reactor inclined at $1^{\circ}, \mathrm{Re}=9000$, and water depth $=5.6 \mathrm{~mm}$ for (a) aspect ratio $=180$ and (b) aspect ratio $=340$ in June (XY-plane).

varied in response to atmospheric temperature or seasonal change to maximise algal yield.

Figure 9 presents the effect of water depth on the temperature distribution of the air-water surface at a Re of 9000 and $\mathrm{AR}=180$ in June (daytime). The temperature fluctuations are considerably less for reactors with small water depth. The light penetration was reduced with the increase in water depth because of the increase in liquid volume, which further decreased the temperature at the airwater surface, as shown in Figure 9(b). The low variance in temperature of less deep reactors helped achieve the optimum water temperatures and as a result, the photosynthetic efficiency of algal cells was significantly increased. Moreover, the small cultural thickness in the TLC reactor prevents strong photoinhibition at a high solar intensity and low culture temperature, which is a common problem in conventional raceway ponds $[8,16]$. However, the $\mathrm{CO}_{2}$ absorption of open photobioreactors increases with the increase in water depth. Therefore, an optimum value of water depth must be selected to maintain the optimum water temperature and increase the $\mathrm{CO}_{2}$ absorption from the atmosphere for improved algal productivity.

4.1.2. Effect of Flow Properties. TLC systems are characterised by highly turbulent flows. Increased turbulence, which improves the exchange rates of nutrients and increases light/dark frequencies, reduces cell sedimentation, 


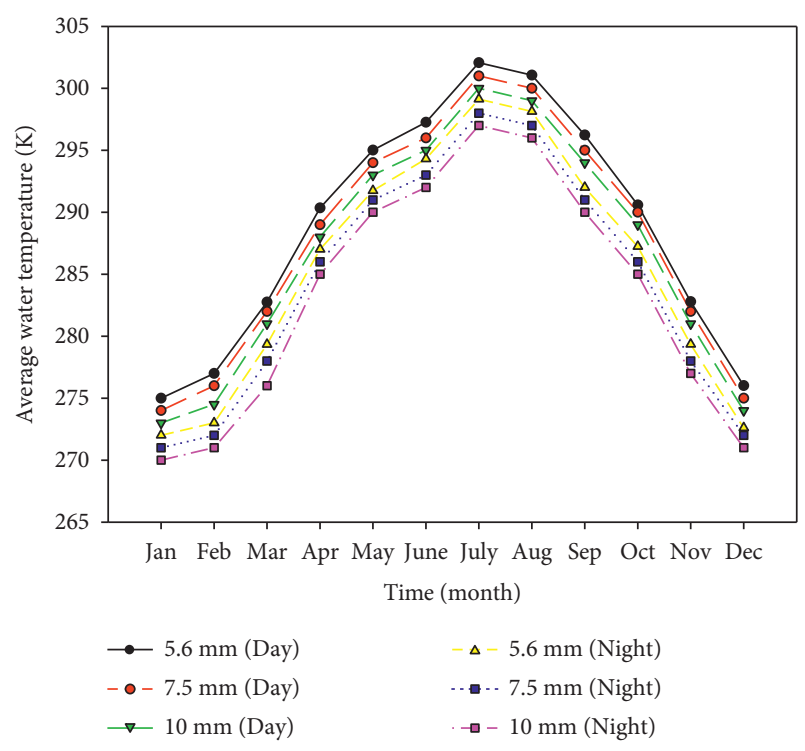

Figure 8: Effect of water depth on average water temperature for reactor inclined at $1^{\circ}, \operatorname{Re}=9000$, and aspect ratio $=180$.

and increases photosynthetic efficiency and productivity. Therefore, the effect of Re on the monthly average water temperature for the TLC reactor inclined at $1^{\circ}$ and at a water depth of $5.6 \mathrm{~mm}$ is presented in Figure 10. Increased Re resulted in increased turbulence that facilitates the heat transfer rate between the reactor water surface and atmosphere. The increase in heat transfer rate reduced the water temperature. For instance, the average day water temperatures at a Re of 9000 for the months of January, June, and December were observed to be 275,297 , and $276 \mathrm{~K}$, respectively. Similarly, the average water temperatures at a Re of 14000 for the months of January, June, and December were 274,295 , and $274 \mathrm{~K}$, respectively. A decrease in the water temperature of approximately $1^{\circ} \mathrm{C}$ and $2^{\circ} \mathrm{C}$ was observed for these months during the day when the Re increased from 9000 to 14000 . However, due to the increased heat transfer rate at night, the water temperature dropped to $2^{\circ} \mathrm{C}$ and $3^{\circ} \mathrm{C}$ during these months.

4.2. Nu. Heat losses from the reactor to its surroundings are mainly described because of convective heat transfer. Consequently, to characterise the convective heat transfer from the reactor water surface to its surroundings, $\mathrm{Nu}$ is presented in the following section.

4.2.1. Effect of Geometric Properties. The effect of the inclination angle of the reactor on heat transfer was evaluated by computing $\mathrm{Nu}$ in Figure 11. The TLC reactor inclined at a higher angle resulted in increased $\mathrm{Nu}$ because of the high heat losses from the reactor. High values of $\mathrm{Nu}$ correspond to more effective convection in the TLC reactor due to the highly turbulent flow and very small culture depth. Solar irradiance and air temperature were high in summer and during the day; therefore, the heat transfer rate was low during these months and at night, resulting in lower values of $\mathrm{Nu}$ than at night and during winter months. Biomass production improved during the summer season and particularly during the day due to lower heat transfer rates [18].

$\mathrm{Nu}$ is presented for different ARs of the reactor in Figure 12 to characterise the convective heat transfer from the reactor water surface to its surroundings. The ambient air temperature was lower than the reactor water temperature in winter; therefore, heat transfer and $\mathrm{Nu}$ showed high values in the corresponding months. Nu showed higher values in winter and lower values in summer for all the cases of ARs considered in this work. The high values of $\mathrm{Nu}$ indicated that heat transfer due to convection is very high in winter. At night, solar radiation and air temperature were relatively low, thus increasing the rate of heat transfer and $\mathrm{Nu}$. The results indicated that due to the high magnitude of $\mathrm{Nu}$ (convection), the water temperature could drop below the optimum value, which in turn reduced algal productivity. The summer season was ideal for the cultivation of algae because an optimal algal cell temperature was sustained and convection (minimal $\mathrm{Nu}$ ) played an insignificant role during this period. $\mathrm{Nu}$ also increased with the increase in reactor AR. Due to the highly convective heat transfer $(\mathrm{Nu})$ caused by the large surface area offering factor, the heat loss in the reactors with wide channels was high $[19,20]$.

The effect of reactor water depth on $\mathrm{Nu}$ at a Re of 9000 and $\mathrm{AR}=180$ is presented in Figure 13. Nu depends on the hydraulic diameter; therefore, increasing the water depths increased $\mathrm{Nu}$ and consequently enhanced the heat transfer rate between the reactor and atmosphere. $\mathrm{Nu}$ showed higher values in winter and lower values in summer for all reactor depths. Nu significantly increased at night and particularly during the winter months because of high heat loss from the reactor caused by relatively low solar irradiation and air temperature values.

4.2.2. Effect of Flow Properties. The effect of Re on heat transfer rate was also analysed by computing $\mathrm{Nu}$, as shown in Figure 14. With the increase in Re, the relative motion between the air-water surface and the velocity of the fluid increased, which decreased the water temperature, thus increasing the temperature difference between water and atmosphere. Greater temperature difference resulted in high heat losses from the reactor to the atmosphere. Heat losses were high during the winter season and at night due to the low air temperature and solar irradiance, consequently resulting in a high value of $\mathrm{Nu}$. These results implied that a certain range of turbulence values increases algal productivity without affecting the optimum water temperature and mechanical structure of the cell $[44,45]$.

4.3. Evaporation. Evaporative cooling caused by the heat transfer from the reactor water surface to its surroundings significantly affects the optimum water temperature. Selfregulation of temperature is one of the primary advantages of TLC systems, as the culture is quickly heated by solar irradiance and cooled by increased evaporation when it overheats. Meanwhile, evaporation largely contributes to the thermodynamics of the reactor by affecting the optimum 


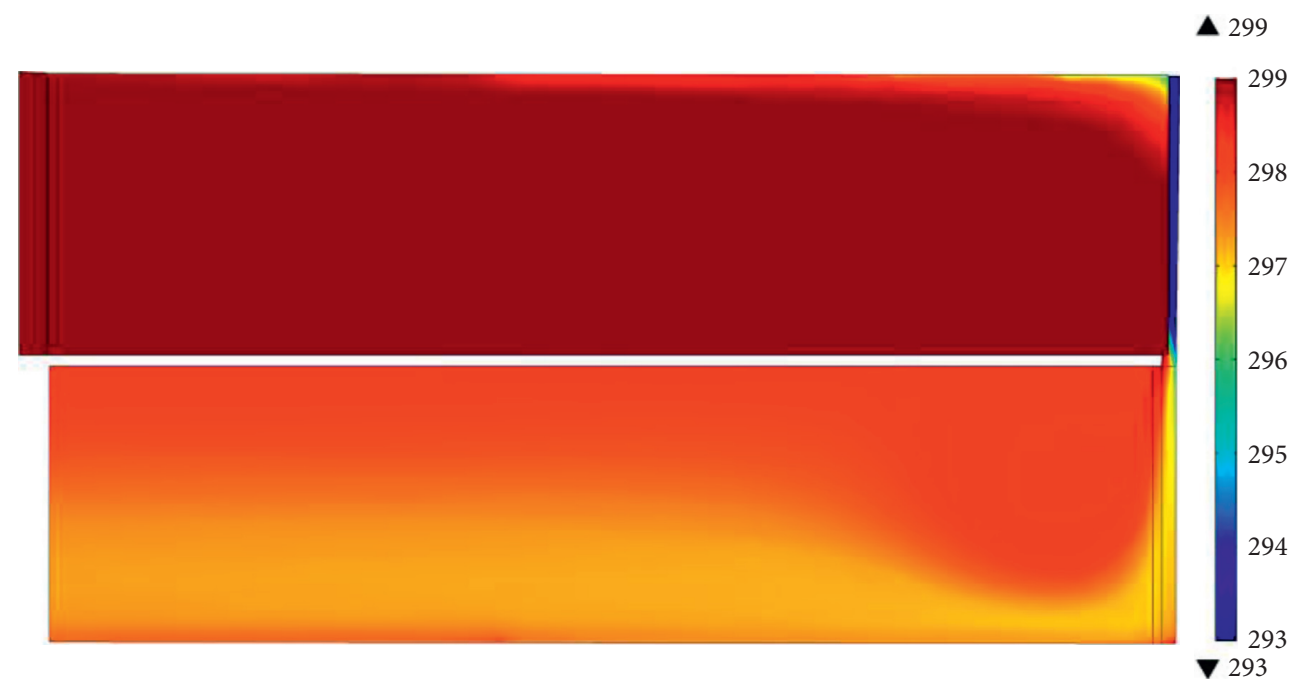

(a)

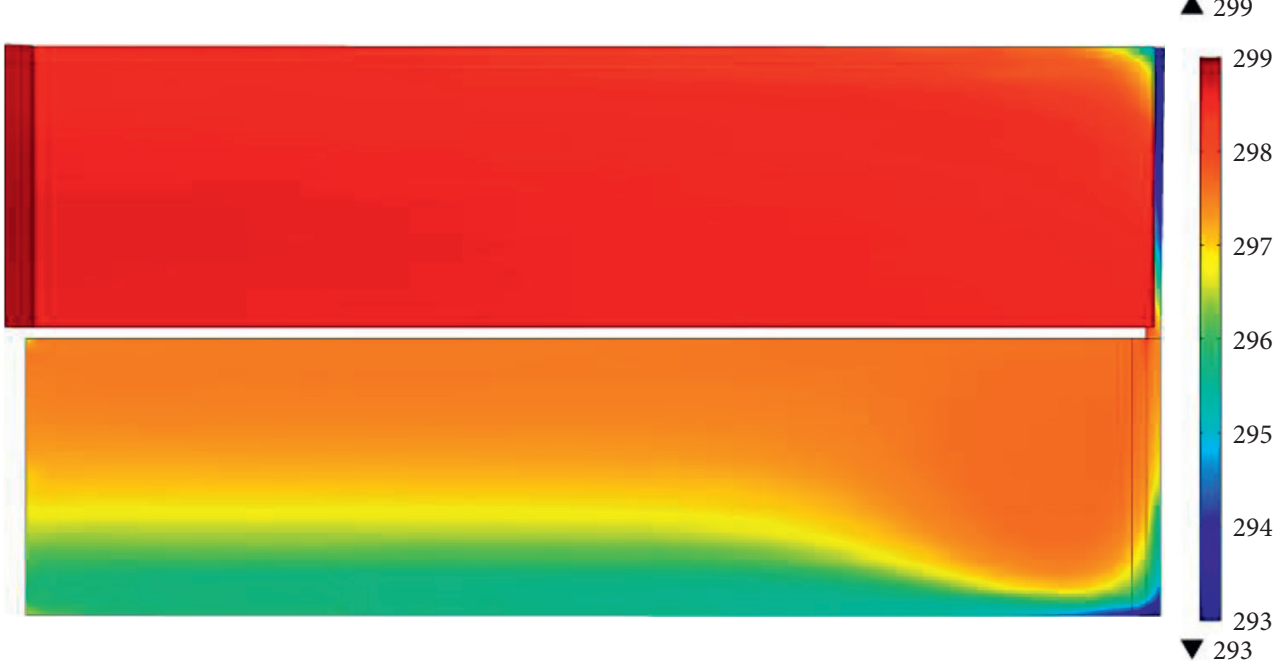

(b)

FIGURE 9: Effect of water depth on air-water surface temperature distribution $\mathrm{K}$ for reactor inclined at $1^{\circ}, \mathrm{Re}=9000$, and aspect ratio $=180$ for (a) $5.6 \mathrm{~mm}$ and (b) $10 \mathrm{~mm}$ in June (XY-plane).

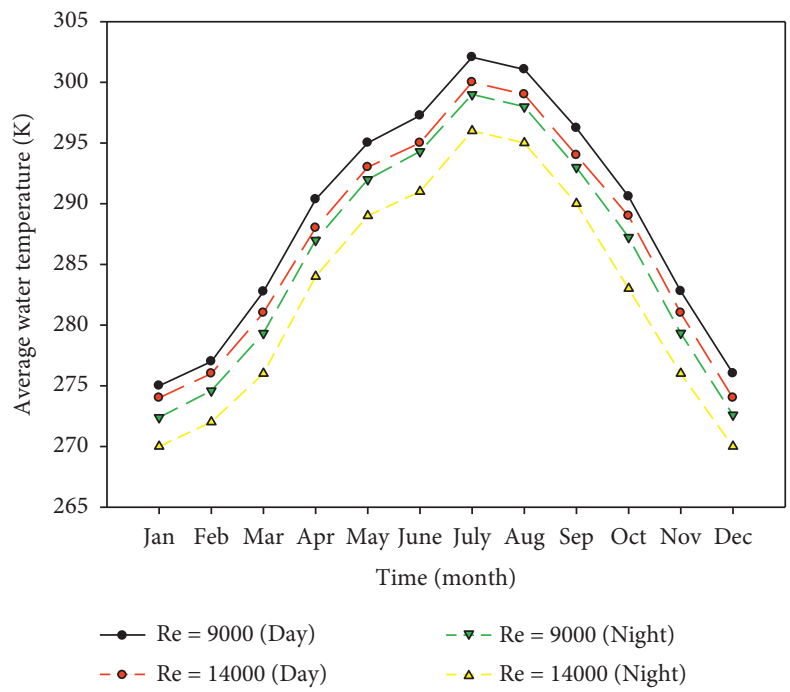

Figure 10: Effect of Re on average water temperature for reactor inclined at $1^{\circ}$, water depth $=5.6 \mathrm{~mm}$, and aspect ratio $=180$. 


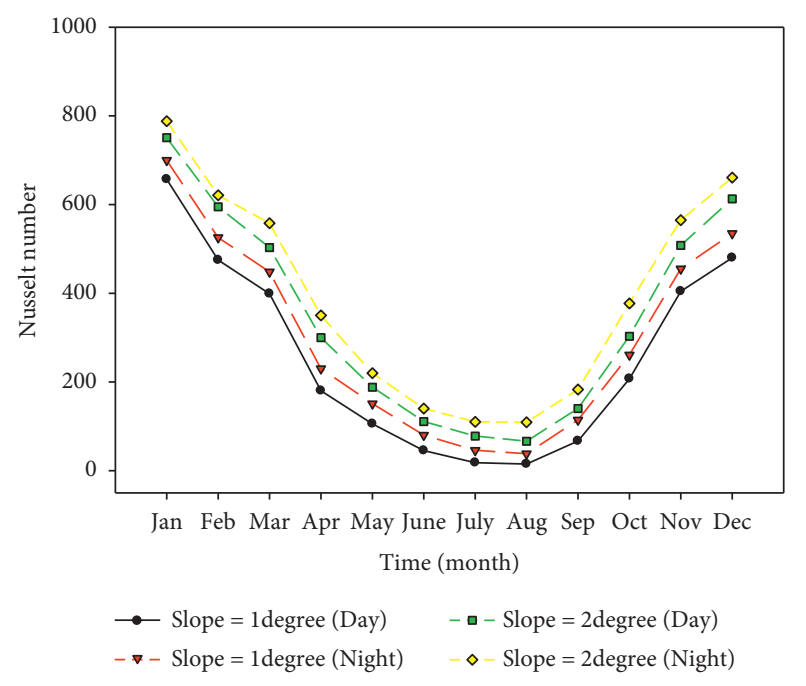

FIGURE 11: Effect of the inclination angle of the reactor on Nusselt number at $\operatorname{Re}=9000$, water depth $=5.6 \mathrm{~mm}$, and aspect ratio $=180$.

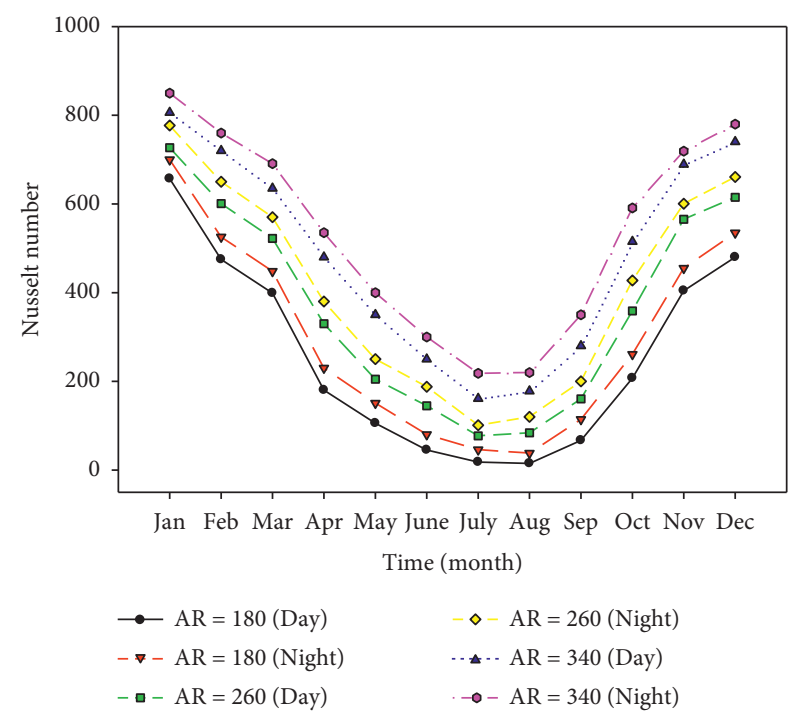

Figure 12: Effect of aspect ratio on Nusselt number for reactor inclined at $1^{\circ}, \mathrm{Re}=9000$, and water depth $=5.6 \mathrm{~mm}$.

water temperature. In addition, the estimation of evaporated water from the reactor is needed to accurately assess the water demand and cost of algal farming. Thus, the monthly evaporated water from the reactor surface is presented in the following section.

4.3.1. Effect of Geometric Properties. The effect of reactor slope angle on the monthly average evaporated water from the reactor surface at a $\operatorname{Re}$ of 9000 , a water depth of $5.6 \mathrm{~mm}$, and $\mathrm{AR}=180$ is presented in Figure 15. For water molecules to evaporate, they must be located near the air-water surface and should have sufficient kinetic energy to overcome liquid-phase intermolecular forces. The turbulence in the flow induced by the higher slope angle of the reactor assisted the warm water molecules to come to the air-water surface and replace the warm ones that evaporated from the surface. The

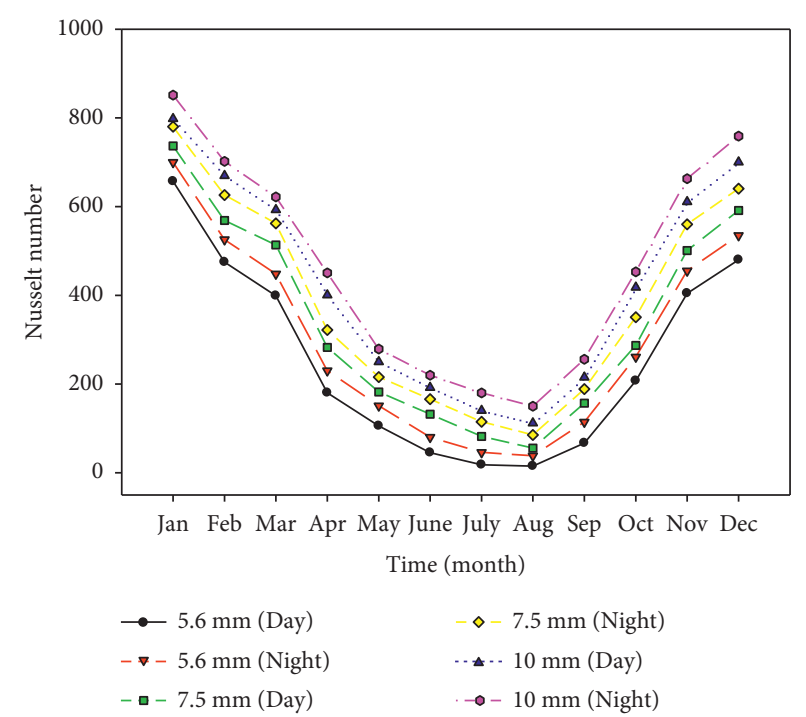

Figure 13: Effect of water depth on Nusselt number for reactor inclined at $1^{\circ}, \operatorname{Re}=9000$ and aspect ratio $=180$.

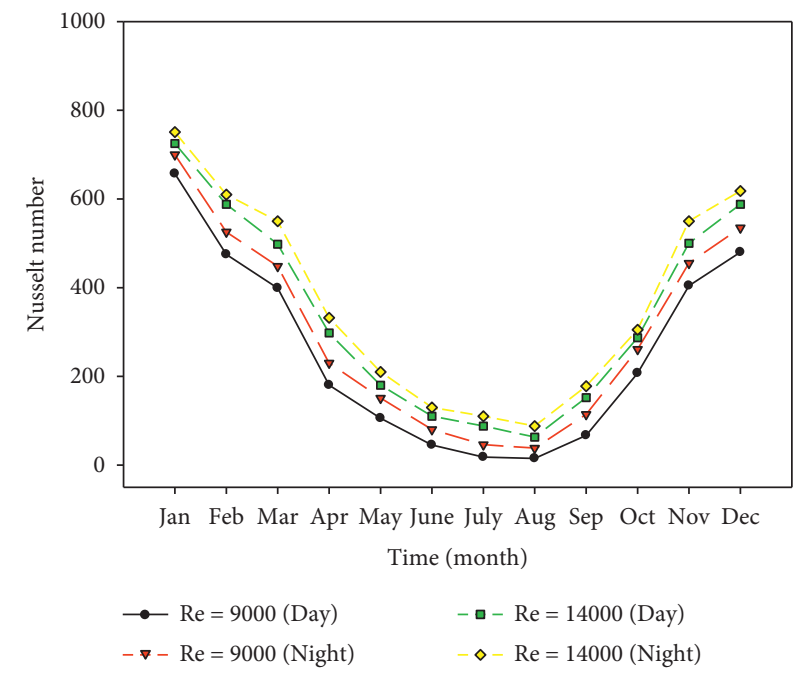

FIGURE 14: Effect of Re on Nusselt number for reactor inclined at $1^{\circ}$, water depth $=5.6 \mathrm{~mm}$ and aspect ratio $=180$.

evaporation rate increased during the summer season, followed by the autumn months due to high solar irradiance and air temperature. For the reactor inclined at $2^{\circ}$, a maximum increase of approximately $3 \mathrm{~kg}$ of water was observed during the summer season in August. These findings showed that an appropriate inclination angle of the reactor must be chosen to ensure that algal growth must not be decreased due to the increase in evaporation rate [46].

The effect of ARs on the monthly evaporated water from the reactor surface at a water depth of $5.6 \mathrm{~mm}$ and a Re of 9000 is presented in Figure 16. The evaporation rate was mainly based on solar intensity, air temperature, air speed, air-water surface water temperature, air humidity, and airwater surface area. The evaporative heat transfer increased in summer due to the high ambient air temperature and solar intensity levels. During winters, evaporative losses were expected to increase due to the lower relative humidity. 


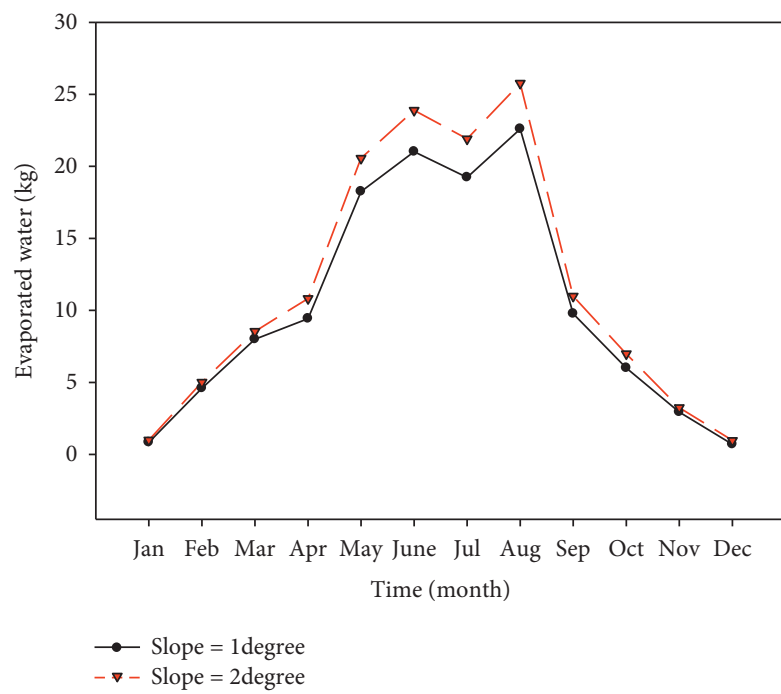

FIGURE 15: Effect of the inclination angle of the reactor on monthly evaporated water at. $R e=9000$, water depth $=5.6 \mathrm{~mm}$, and aspect ratio $=180$.

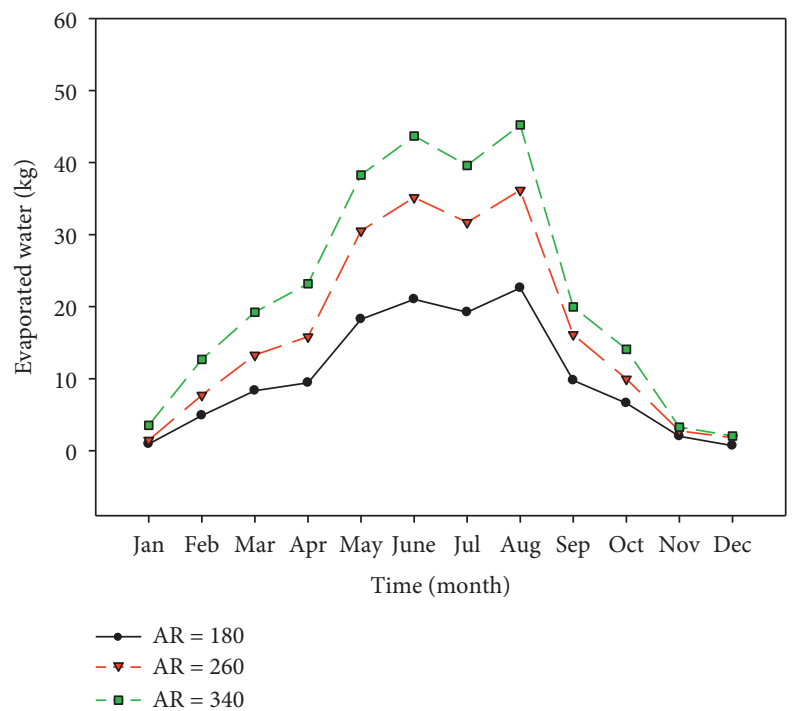

FIGURE 16: Effect of aspect ratio on monthly evaporated water for reactor inclined at $1^{\circ}, \mathrm{Re}=9000$, and water depth $=5.6 \mathrm{~mm}$.

However, in winter, evaporation decreased substantially due to the lower solar radiation and ambient air temperature. The increase in AR also increased the amount of evaporated water because of an increase in the air-water surface area. The maximum increase in evaporated water of approximately $20 \mathrm{~kg}$ in June was observed, with an increase in AR from 180 to 340 in June. An increase in the amount of evaporated water with an increase in the AR values resulted in decreased water temperature of the reactor. These findings indicated that the algal cells decreased in the reactor with high ARs due to the high amount of evaporated water. An appropriate channel width must be selected to maximise algal productivity at reduced evaporative losses.

The effect of reactor water depths on the monthly amount of evaporated water at $\mathrm{AR}=180$ and a Re of 9000 is presented in Figure 17. The evaporation rate decreased with rising water depth because the warm water molecules failed to reach the top surface of the reactor. Maximum decreases of 4 and $11 \mathrm{~kg}$ were observed for water depths of $7.5 \mathrm{~mm}$ and $10 \mathrm{~mm}$ in June, respectively. Increasing the water depth reduced the light penetration and optimum water temperature. Moreover, the photosynthetic efficiency of algal cells decreased in deeper TLC systems. However, the $\mathrm{CO}_{2}$ absorption efficiency of deep reactors was comparatively higher than that of reactors with small culture depth. Therefore, an appropriate water depth must be selected to reduce heat loss, maintain the optimum water temperature, and increase $\mathrm{CO}_{2}$ absorption efficiency $[20,43]$.

4.3.2. Effect of Flow Properties. The effect of Re on the monthly evaporated water from the reactor surface inclined 


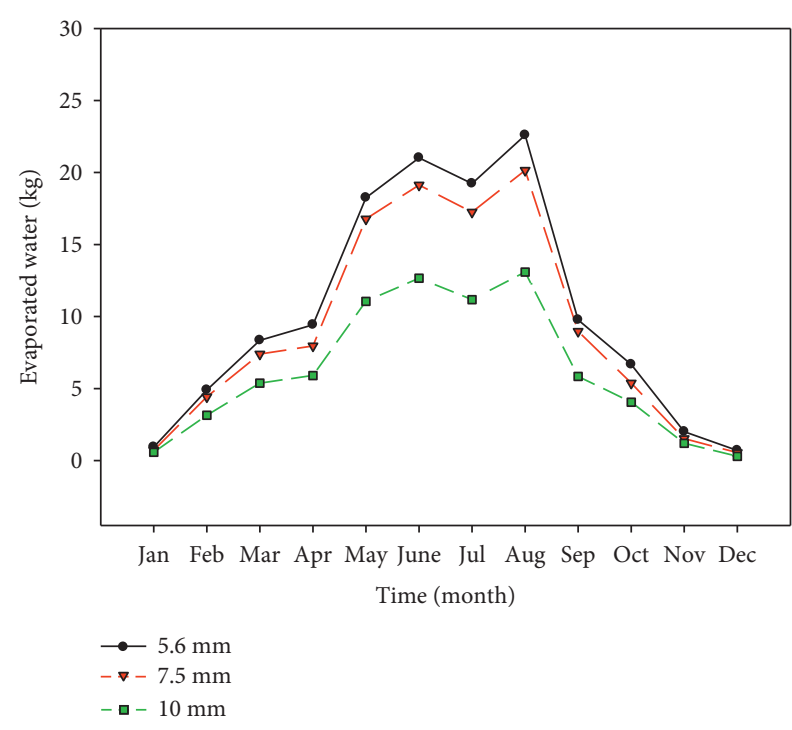

Figure 17: Effect of water depth on monthly evaporated water for reactor inclined at $1^{\circ}, \operatorname{Re}=9000$, and aspect ratio $=180$.

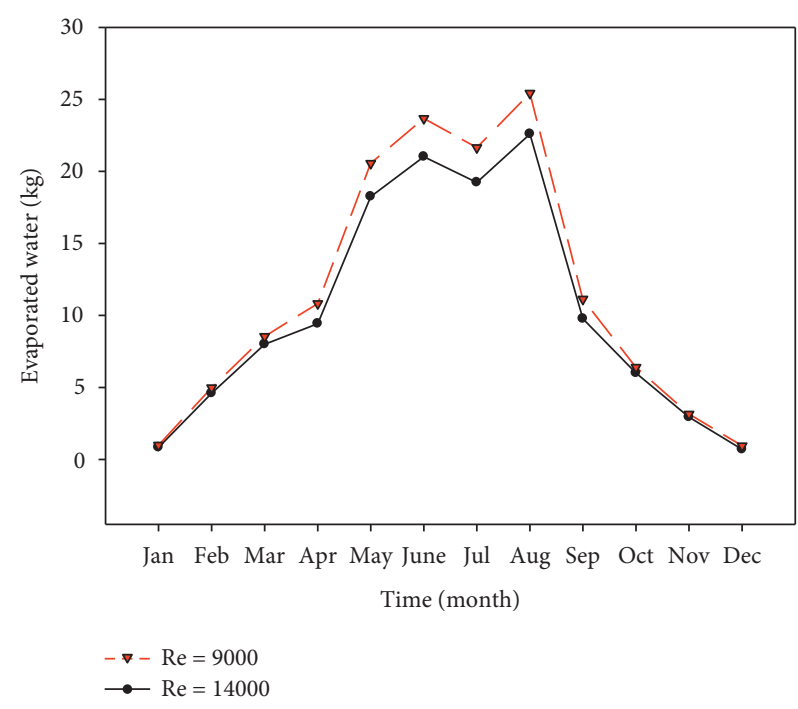

FIGURE 18: Effect of Re on monthly evaporated water for reactor inclined at $1^{\circ}$, water depth $=5.6 \mathrm{~mm}$, and aspect ratio $=180$.

at a slope angle of $1^{\circ}$ and a water depth of $5.6 \mathrm{~mm}$ is presented in Figure 18. The evaporation tended to proceed more quickly at high Re. The high Re increased the kinetic energy of the water molecule and consequently resulted in increased evaporation. The evaporation rate was maximum in February, May, August, and September for winter, spring, summer, and autumn months, respectively, where increases of approximately $0.08,2.31,3$, and $1.36 \mathrm{~kg}$ were observed by increasing the Re from $2.4 \mathrm{~kg} / \mathrm{s}$ to $3.6 \mathrm{~kg} / \mathrm{s}$ for the respective months. The effect of $\mathrm{Re}$ on evaporation rate tended to be small compared to the geometrical parameters of the reactor. However, an appropriate value of $\mathrm{Re}$ must be selected without damaging the algal cell structure to minimise the operational cost [44].

\section{Conclusion}

This study presents a numerical investigation on the heat transfer between TLC reactor and atmosphere with the effect of reactor geometric properties, hydrodynamics, and environmental conditions (air temperature, relative humidity, solar intensity, and air speed). Heat transfer analysis was conducted using monthly water temperature, $\mathrm{Nu}$, and the amount of evaporated water. The abovementioned parameters were studied by considering various aspect ratios, water depth, and slope angle of the reactor. A novel correlation was employed to quantify the amount of evaporated water in a thin-layer cascade reactor. The main conclusions of the study are summarised as follows:

(i) The findings suggest that installing reactor at lower slopes with small reactor dimensions appears beneficial in terms of achieving optimal temperatures for algal growth. The increase in channel width, slope angle, and water depth resulted in an increased heat transfer rate, which negatively affected the optimal water temperature.

(ii) The reactor achieved an optimal temperature of $302 \mathrm{~K}$ during the summer season in the month of August. Due to the high heat transfer rate during the winter season, the temperature reduced to its lowest value of $(268 \mathrm{~K})$ in the month of January.

(iii) The increase in AR, slope angle, and Re increased water losses. The evaporation rate was high in February, May, August, and September for winter, spring, summer, and autumn months, respectively, where a maximum of $45 \mathrm{~kg}$ water evaporated from reactor surface in the month of August.

TLC reactors are an effective means to integrate light in open photobioreactors and might replace the inefficient raceway ponds. However, an appropriate inclination angle of the reactor and channel width must be chosen to achieve optimal temperature for algal growth. Even though the design of the TLC reactor was proposed a long time ago, it still needs to be optimised for commercial-scale production of microalgae.

\section{Abbreviations}

$A R: \quad$ Aspect ratio (1)

$D: \quad$ Diffusion coefficient $\left(\mathrm{m}^{2} / \mathrm{s}\right)$

$d$ : Water depth $(\mathrm{m})$

$u$ : Velocity vector $(\mathrm{m} / \mathrm{s})$

$W: \quad$ Channel width $(\mathrm{m})$

A: $\quad$ Cross sectional area $\left(\mathrm{m}^{2}\right)$

c: Water vapor concentration $\left(\mathrm{mol} / \mathrm{m}^{3}\right)$

$c_{\text {vap }}$ : Concentration of water vapor $\left(\mathrm{mol} / \mathrm{m}^{3}\right)$

$h$ : Heat transfer coefficient of air $\left(\mathrm{W} /\left(\mathrm{m}^{2} \mathrm{~K}\right)\right.$

L: $\quad$ Length (m)

$D_{h}: \quad$ Hydraulic diameter $(\mathrm{m})$

$\mathrm{F}_{\mathrm{amb}}$ : Ambient view factor (1)

$F_{\text {ext }}$ : External view factor (1)

$H_{\text {vap }}$ : Latent heat of vaporisation $(\mathrm{kJ} / \mathrm{mol})$ 
$G_{\text {amb }}:$ Ambient irradiance $\left(\mathrm{W} / \mathrm{m}^{2}\right)$

$e_{b}(T)$ : Blackbody total emissive power $\left(\mathrm{W} / \mathrm{m}^{2}\right)$

$p_{\text {sat }}: \quad$ Saturation pressure $(\mathrm{Pa})$

$I_{s}: \quad$ Incident radiative intensity from sun $\left(\mathrm{W} / \mathrm{m}^{2}\right)$

$S c_{T}: \quad$ Schmidt number (1)

$\mathrm{Nu}$ : $\quad$ Nusselt number (1), $\mathrm{hD}_{\mathrm{h}} / \lambda$

Re: $\quad$ Reynolds number (1)

$R_{g}$ : Ideal gas constant $(\mathrm{J} / \mathrm{mol} \mathrm{K})$

$T_{\mathrm{amb}}:$ Ambient temperature $(\mathrm{K})$

$T_{a}$ : $\quad$ Monthly mean ambient temperature $(\mathrm{K})$

$M_{w}: \quad$ Molar mass of water $(\mathrm{kg} / \mathrm{mol})$

$m_{w}$ : Amount of evaporated water $(\mathrm{kg})$

$u_{a}: \quad$ Mean air speed $(\mathrm{m} / \mathrm{s})$

I: Identity matrix

$J: \quad$ Radiosity or radiative flux $\left(\mathrm{W} / \mathrm{m}^{2}\right)$

$t: \quad$ Time (h)

$j: \quad$ Diffusive flux in $z$-direction $\left(\mathrm{mol} / \mathrm{m}^{2} \mathrm{~s}\right)$

$n: \quad$ Transparent medium refractive index (1)

q: $\quad$ Heat flux $\left(\mathrm{W} / \mathrm{m}^{2}\right)$

T: $\quad$ Water temperature $(\mathrm{K})$

u: $\quad$ Water velocity $(\mathrm{m} / \mathrm{s})$

$k$ : Turbulent kinetic energy $\left(\mathrm{m}^{2} / \mathrm{s}^{2}\right)$

$\rho: \quad$ Water density $\left(\mathrm{kg} / \mathrm{m}^{3}\right)$

$\mu_{t}: \quad$ Turbulent viscosity (Pa.s)

$\varphi: \quad$ Relative humidity (\%)

$\omega: \quad$ Turbulent dissipation rate $(1 / \mathrm{s})$

$\mu$ : Water viscosity $\left(\mathrm{m}^{2} / \mathrm{s}\right)$

$\varepsilon: \quad$ Surface emissivity (1)

$\sigma: \quad$ Stefan-Boltzmann constant $\left(\mathrm{W} / \mathrm{m}^{2} \mathrm{~K}^{4}\right)$

$\sigma_{\omega}: \quad$ Prandtl number for dissipation rate

$\sigma_{k}: \quad$ Prandtl number for kinetic energy

$\alpha: \quad$ Thermal diffusivity $\left(\mathrm{m}^{2} / \mathrm{s}\right)$

$\lambda: \quad$ Thermal conductivity of water $(\mathrm{W} /(\mathrm{m} \mathrm{K}))$.

\section{Data Availability}

All data analysed during this study are included in the article.

\section{Conflicts of Interest}

The authors declare that they have no conflicts of interest.

\section{Acknowledgments}

This study was supported by the National Research Foundation of Korea and funded by the Korean government (MSIP, grant nos. 2020R1A2B5B02002512 and 2020R1A4A1018652).

\section{References}

[1] C. Posten and C. Walter, Microalgal Biotechnology: Potential and Production, Walter de Gruyter, Berlin, Germany, 2012.

[2] F. G. Acién, C. Gómez-Serrano, M. M. Morales-Amaral, J. M. Fernández-Sevilla, and E. Molina-Grima, "Wastewater treatment using microalgae: how realistic a contribution might it be to significant urban wastewater treatment?" Applied Microbiology and Biotechnology, vol. 100, no. 21, pp. 9013-9022, 2016.
[3] T. M. M. Bernaerts, A. Panozzo, V. Doumen et al., "Microalgal biomass as a (multi)functional ingredient in food products: rheological properties of microalgal suspensions as affected by mechanical and thermal processing," Algal Research, vol. 25, pp. 452-463, 2017.

[4] T. M. Mata, A. A. Martins, and N. S. Caetano, "Microalgae for biodiesel production and other applications: a review," Renewable and Sustainable Energy Reviews, vol. 14, no. 1, pp. 217-232, 2010.

[5] R. S. Gour, A. Chawla, H. Singh, R. S. Chauhan, and A. Kant, "Characterization and screening of native Scenedesmus sp. isolates suitable for biofuel feedstock," PLoS One, vol. 11, no. 5, Article ID e0155321, 2016.

[6] O. Pulz, "Photobioreactors: production systems for phototrophic microorganisms," Applied Microbiology and Biotechnology, vol. 57, no. 3, pp. 287-293, 2001.

[7] I. Setlík, V. Sust, and I. Málek, "Dual purpose open circulation units for large scale culture of algae in temperate zones. I. Basic design considerations and scheme of a pilot plant," Algological Studies/Archiv für Hydrobiologie Supplement, vol. 1, pp. 111-164, 1970.

[8] J. Doucha and K. Lívanský, "Outdoor open thin-layer microalgal photobioreactor: potential productivity," Journal of Applied Phycology, vol. 21, no. 1, pp. 111-117, 2009.

[9] J. Doucha and K. Lívanský, "Novel outdoor thin-layer high density micro algal culture system: productivity and operational parameters," Algological Studies/Archiv für Hydrobiologie, Supplement, vol. 76, pp. 129-147, 1995.

[10] J. Masojídek, J. Kopecký, L. Giannelli, and G. Torzillo, "Productivity correlated to photobiochemical performance of chlorella mass cultures grown outdoors in thin-layer cascades," Journal of Industrial Microbiology \& Biotechnology, vol. 38, no. 2, pp. 307-317, 2011.

[11] A. Chiarini and M. Quadrio, "The light/dark cycle of microalgae in a thin-layer photobioreactor," Journal of Applied Phycology, vol. 33, pp. 1-13, 2020.

[12] B. Behera, A. Acharya, I. A. Gargey, N. Aly, and P. Balasubramanian, "Bioprocess engineering principles of microalgal cultivation for sustainable biofuel production," Bioresource Technology Reports, vol. 5, pp. 297-316, 2019.

[13] J. U. Grobbelaar, "Factors governing algal growth in photobioreactors: the "open" versus "closed" debate," Journal of Applied Phycology, vol. 21, no. 5, pp. 489-492, 2009.

[14] A. C. Apel, C. E. Pfaffinger, N. Basedahl et al., "Open thinlayer cascade reactors for saline microalgae production evaluated in a physically simulated Mediterranean summer climate," Algal Research, vol. 25, pp. 381-390, 2017.

[15] A. P. Koller, H. Löwe, V. Schmid, S. Mundt, and D. Weuster-Botz, "Model-supported phototrophic growth studies with Scenedesmus obtusiusculus in a flat-plate photobioreactor," Biotechnology and Bioengineering, vol. 114, no. 2, pp. 308-320, 2017.

[16] J. U. Grobbelaar, L. Nedbal, L. Tichy, and L. Setlik, "Variation in some photosynthetic characteristics of microalgae cultured in outdoor thin-layered sloping reactors," Journal of Applied Phycology, vol. 7, no. 2, pp. 175-184, 1995.

[17] J. Doucha and K. Lívanský, "Productivity, CO2/O2 exchange and hydraulics in outdoor open high density microalgal (Chlorella sp.) photobioreactors operated in a middle and Southern European climate," Journal of Applied Phycology, vol. 18, no. 6, pp. 811-826, 2006.

[18] J. L. Drewry, C. Y. Choi, L. An, and P. E. Gharagozloo, “A computational fluid dynamics model of algal growth: development and validation," Transactions of the American Society 
of Agricultural and Biological Engineers, vol. 58, no. 2, pp. 203-213, 2015.

[19] E. Sforza, D. Simionato, G. M. Giacometti, A. Bertucco, and T. Morosinotto, "Adjusted light and dark cycles can optimize photosynthetic efficiency in algae growing in photobioreactors," PLoS One, vol. 7, no. 6, Article ID e38975, 2012.

[20] R. Bouterfas, M. Belkoura, and A. Dauta, "Light and temperature effects on the growth rate of three freshwater algae isolated from a eutrophic lake," Hydrobiologia, vol. 489, no. 1/ 3, pp. 207-217, 2002.

[21] R. G. Wetzel, "Photosynthesis, productivity and growth: the physiological ecology of phytoplankton," Aquatic Botany, vol. 9, pp. 98-99, 1980.

[22] A. Cossins, Temperature Biology of Animals, Springer Science \& Business Media, Berlin, Germany, 2012.

[23] C. Bosca, A. Dauta, and O. Marvalin, "Intensive outdoor algal cultures: how mixing enhances the photosynthetic production rate," Bioresource Technology, vol. 38, no. 2-3, pp. 185-188, 1991.

[24] S. Banerjee and S. Ramaswamy, "Dynamic process model and economic analysis of microalgae cultivation in open raceway ponds," Algal Research, vol. 26, pp. 330-340, 2017.

[25] H. Ali, T. A. Cheema, and C. W. Park, "Numerical prediction of heat transfer characteristics based on monthly temperature gradient in algal open raceway ponds," International Journal of Heat and Mass Transfer, vol. 106, pp. 7-17, 2017.

[26] C. Quiroz-Arita, M. L. Blaylock, P. E. Gharagozloo et al., "A dynamic thermal algal growth model for pilot-scale openchannel raceways," Bioresource Technology Reports, vol. 10, Article ID 100405, 2020.

[27] D. C. Wilcox, "Simulation of transition with a two-equation turbulence model," AIAA Journal, vol. 32, no. 2, pp. 247-255, 1994.

[28] D. C. Wilcox, Turbulence Modelling for CFD, DCW Industries, Los Angeles, CA, USA, 1998.

[29] V. T. Chow, Open-Channel Hydraulics, McGraw-Hill, New York, NY, USA, 1959.

[30] A. B. Comsol, Heat Transfer Module User's Guide, COMSOL Multiphysics, Stockholm, Sweden, 2018.

[31] Q. Béchet, A. Shilton, J. B. K. Park, R. J. Craggs, and B. Guieysse, "Universal temperature model for shallow algal ponds provides improved accuracy," Environmental Science \& Technology, vol. 45, no. 8, pp. 3702-3709, 2011.

[32] T. L. Bergman, F. P. Incropera, D. P. DeWitt, and A. S. Lavine, Fundamentals of Heat and Mass Transfer, John Wiley \& Sons, New York, NY, USA, 2011.

[33] A. R. Esteve, V. Estellés, M. P. Utrillas, and J. A. MartínezLozano, "In-situ integrating nephelometer measurements of the scattering properties of atmospheric aerosols at an urban coastal site in western Mediterranean," Atmospheric Environment, vol. 47, pp. 43-50, 2012.

[34] A. Greve and M. Bremer, Thermal Design and Thermal Behaviour of Radio Telescopes and Their Enclosures, Springer Science \& Business Media, Berlin, Germany, 2010.

[35] F. P. Incropera, A. S. Lavine, T. L. Bergman, and D. P. DeWitt, Fundamentals of Heat and Mass Transfer, Wiley, New York, NY, USA, 2007.

[36] A. B. Comsol, CFD Module User's Guide, COMSOL, Stockholm, Sweden, 2015.

[37] A. B. Comsol, Chemical Engineering Module User's Guide (COMSOL 3.5 a), COMSOL, Stockholm, Sweden, 2008.

[38] M. F. Modest, Radiative Heat Transfer, Academic Press, Cambridge, MA, USA, 2013.

[39] Y. Chisti, "Biodiesel from microalgae," Biotechnology Advances, vol. 25, no. 3, pp. 294-306, 2007.
[40] Korea Meteorological Administration, Annual Climatological Report, Korea Meteorological Administration, Seoul, South Korea, 2017.

[41] I. R. Davison, "Environmental effects on algal photosynthesis: temperature," Journal of Phycology, vol. 27, no. 1, pp. 2-8, 1991.

[42] J. A. Raven and R. J. Geider, "Temperature and algal growth," New Phytologist, vol. 110, no. 4, pp. 441-461, 1988.

[43] D. Simionato, S. Basso, G. M. Giacometti, and T. Morosinotto, "Optimization of light use efficiency for biofuel production in algae," Biophysical Chemistry, vol. 182, pp. 71-78, 2013.

[44] W. H. Thomas and C. H. Gibson, "Effects of small-scale turbulence on microalgae," Journal of Applied Phycology, vol. 2, no. 1, pp. 71-77, 1990.

[45] J. U. Grobbelaar, "Turbulence in mass algal cultures and the role of light/dark fluctuations," Journal of Applied Phycology, vol. 6, no. 3, pp. 331-335, 1994.

[46] T. de Marchin, M. Erpicum, and F. Franck, "Photosynthesis of Scenedesmus obliquus in outdoor open thin-layer cascade system in high and low CO2 in Belgium," Journal of Biotechnology, vol. 215, pp. 2-12, 2015. 